\title{
Combining theory and experiment to get insight into the amorphous phase of luminescent mechanochromic copper iodide clusters
}

Raquel Utrera-Melero, ${ }^{a}$ Brendan Huitorel, ${ }^{b}$ Marie Cordier, ${ }^{c}$ Jean-Yves Mevellec, ${ }^{a}$ Florian Massuyeau, ${ }^{a}$ Camille Latouche, ${ }^{a *}$ Charlotte Martineau-Corcos, ${ }^{d, e *}$ and Sandrine Perruchas ${ }^{a, b *}$

${ }^{a}$ Université de Nantes, CNRS, Institut des Matériaux Jean Rouxel, IMN, F-44000 Nantes, France. Phone: (+33) (0)2 403763 35. E-mail: sandrine.perruchas@cnrs-imn.fr

${ }^{\mathrm{b}}$ Laboratoire de Physique de la Matière Condensée (PMC), CNRS - Ecole Polytechnique, 91128 Palaiseau Cedex, France.

${ }^{\mathbf{c}}$ Laboratoire de Chimie Moléculaire, CNRS - Ecole Polytechnique, 91128 Palaiseau Cedex, France.

${ }^{\mathrm{d}}$ MIM, Institut Lavoisier de Versailles (ILV), UMR CNRS 8180, Université de Versailles St-Quentin en Yvelines (UVSQ), 45, avenue des Etats-Unis, 78035 Versailles Cedex, France.

${ }^{\text {e }}$ CNRS, CEMHTI UPR 3079, Université d’Orléans, F-45071 Orléans, France. 


\begin{abstract}
In the field of stimuli-responsive luminescent materials, mechanochromic compounds exhibiting reversible emission color changes activated by mechanical stimulation, present appealing perspectives in sensor applications. The mechanochromic luminescence properties of the molecular cubane copper iodide cluster $\left[\mathrm{Cu}_{4} \mathrm{I}_{4}\left(\mathrm{PPh}_{2}\left(\mathrm{C}_{6} \mathrm{H}_{4}-\mathrm{CH}_{2} \mathrm{OH}\right)\right)_{4}\right]$ (1), are reported in this study. This compound can form upon melting an amorphous phase giving an unprecedented opportunity to investigate the mechanochromism phenomenon. Because the mechanically induced crystalline-toamorphous transition is only partial, the completely amorphous phase represents the ultimate state of the mechanically altered phase. Furthermore, the studied compound could form two different crystalline polymorphs namely $\mathbf{1} \cdot \mathbf{C H}_{\mathbf{3}} \mathbf{C N}$ and $\mathbf{1} \cdot \mathbf{T H F}$, allowing establishment of straightforward structureproperties relationships. Photophysical and structural characterizations of $\mathbf{1}$ in different states were performed and the experimental data were supported by theoretical investigations. Solid-state NMR (Nuclear Magnetic Resonance) analysis permit to quantify the amorphous part in the mechanically altered phase. IR (Infra-Red) and Raman analysis enabled identification of the spectroscopic signatures of each states. DFT (density functional theory) calculations led to assignment of both the NMR characteristics and the vibrational bands. Rationalization of the photoluminescence properties was also conducted with simulation of the phosphorescence spectra allowing an accurate interpretation of the thermochromic luminescence properties of this family of compounds. The combined study of crystalline polymorphism and amorphous state permit to get deeper into the mechanochromism mechanism that implies changes of the $\left[\mathrm{Cu}_{4} \mathrm{I}_{4}\right]$ cluster core geometry. By combining multi-stimuli responsive properties, copper iodide clusters constitute an appealing class of compounds towards original functional materials.
\end{abstract}

Keywords. luminescence mechanochromism, copper iodide cluster, amorphous phase, polymorphism, phosphorescence, DFT, vibronic coupling. 


\section{Introduction}

Stimuli-responsive luminescent materials present great applicative perspectives for memory and security systems. ${ }^{1,2,3,4,5,6,7}$ Intense researches are currently devoted to luminescent mechanochromic materials exhibiting reversible emission color changes activated by mechanical stimulation, because of their promising sensor applications. ${ }^{8,9,10,11,12,13,14,15,16,17,18,19,20}$ In the last decade, the number of reports on luminescent mechanochromic compounds keeps increasing ${ }^{21,22}$ with a majority of organic compounds ${ }^{23,24}$ compared with the metal-based ones which are mainly based on gold $^{25}$ and platinum ${ }^{26}$ complexes. Despite this plethora of studies, thorough investigations to understand the mechanisms at play still remain relatively scarce. ${ }^{27}$ Nevertheless, such studies are fundamentally important not only to get insights into mechanochromic mechanisms but also to design and develop new stimuli-responsive materials with targeted optimized properties.

Studies of mechanochromic materials generally show that the application of mechanical forces induces modifications of the structural arrangements and consequently changes of the solid-state photophysical properties. Excepted for limited cases for which crystal-to-crystal transformations are involved, ${ }^{28}$ mechanistic studies are generally arduous due to the high difficulty to characterize the structural changes within the altered compound without the help of single-crystal X-ray analysis. Indeed, a crystalline-toamorphous transition commonly takes place and the transformation is generally incomplete. The low amount combined with the amorphous character of the transformed phase, prevents straightforward structural characterizations. In that case, study of a completely amorphous phase which represents the ultimate state of the altered state, should provide useful information into such mechanically induced transformations. To assure a totally amorphous state, melting process is preferred over fast precipitation. This strategy can be easily envisioned for organic compounds ${ }^{29,30}$ and boron complexes ${ }^{31,32}$ but for metal-based compounds, melting is frequently preceded by decomposition. To our knowledge, the only study of the mechanochromic properties of a metal-based compound in correlation with its amorphous phase obtained through melting process, concerns a gold(I) isocyanide complex. ${ }^{33}$

Copper-based compounds have emerged as relevant mechanochromic materials regarding their large panel of photophysical properties and economic advantages. ${ }^{34,35}$ Copper complexes are actually more accessible and less expensive compared with noble metals and lanthanide ions..$^{36,37,38,39}$ Since the discovery of the mechanochromic luminescence properties of a copper iodide molecular cluster, ${ }^{35 a}$ we have pursued our investigations on the family of copper iodide compounds demonstrating high contrasted emission responses to mechanical solicitations. Among this family, cubane copper iodide clusters formulated $\left[\mathrm{Cu}_{4} \mathrm{I}_{4} \mathrm{~L}_{4}\right]$ ( $\mathrm{L}=$ organic ligand), are particularly appealing because of their multistimuli responsive properties with combination of mechanochromism, thermochromism and even solvatochromism, being particularly attractive for the development of multifunctional materials. ${ }^{35}$ The mechanochromic properties of these compounds have been attributed to modifications of the cuprophilic interactions induced by the applied mechanical stress. Indeed, a shortening of the $\mathrm{Cu}-\mathrm{Cu}$ bond lengths has been evidenced as being responsible for the observed modifications of the emission properties. ${ }^{35 a, b, 40}$ However, up to now, direct characterization of the amorphous phase has not been performed because of partial amorphization. 
Here, we report on the study of the mechanochromic luminescence properties of the cubane copper iodide cluster formulated $\left[\mathrm{Cu}_{4} \mathrm{I}_{4}\left(\mathrm{PPh}_{2}\left(\mathrm{C}_{6} \mathrm{H}_{4}-\mathrm{CH}_{2} \mathrm{OH}\right)\right)_{4}\right]$ (1) which could form a fully amorphous phase upon melting. Photophysical and structural analysis permit to get more insights into the mechanochromism mechanism showing that the amorphous state is the ultimate state of the mechanically induced crystalline-to-amorphous transformation. In particular, solid-state NMR (nuclear magnetic resonance) characterizations allowed us to quantify the amorphous part in the mechanically altered phase. These results are supported by structure-properties relationships which could be established through characterizations of two crystalline polymorphs of the studied compound. IR (infrared) and Raman analysis enable identification of the spectroscopic signatures of the different states of $\mathbf{1}$ (Chart 1). DFT (density functional theory) calculations were conducted and permit a precise assignment of both the NMR characteristics and the vibrational bands. Rationalization of the photoluminescence properties was also possible thanks to the DFT investigations. The phosphorescence emission spectra were simulated allowing an accurate interpretation of the thermochromic luminescence properties of this family of compounds. Although, the study of crystalline polymorphs for the understanding of the mechanochromism mechanism has been already reported, investigating the ultimate state of mechanical solicitation through an amorphous phase, is to our knowledge, unprecedented for copper iodide compounds.

Chart 1. Labels of the different states studied for $\left[\mathrm{Cu}_{4} \mathrm{I}_{4}\left(\mathrm{PPh}_{2}\left(\mathrm{C}_{6} \mathrm{H}_{4}-\mathrm{CH}_{2} \mathrm{OH}\right)\right)_{4}\right] \mathbf{1}$.

$\left[\mathrm{Cu}_{4} \mathrm{I}_{4}\left(\mathrm{PPh}_{2}\left(\mathrm{C}_{6} \mathrm{H}_{4}-\mathrm{CH}_{2} \mathrm{OH}\right)\right)_{4}\right] \cdot 3 \mathrm{THF}$ crystalline polymorph

$\left[\mathrm{Cu}_{4} \mathrm{I}_{4}\left(\mathrm{PPh}_{2}\left(\mathrm{C}_{6} \mathrm{H}_{4}-\mathrm{CH}_{2} \mathrm{OH}\right)\right)_{4}\right] \cdot \mathrm{CH}_{3} \mathrm{CN}$ crystalline polymorph

$\left[\mathrm{Cu}_{4} \mathrm{I}_{4}\left(\mathrm{PPh}_{2}\left(\mathrm{C}_{6} \mathrm{H}_{4}-\mathrm{CH}_{2} \mathrm{OH}\right)\right)_{4}\right] \cdot 3 \mathrm{THF}$ ground

$\left[\mathrm{Cu}_{4} \mathrm{I}_{4}\left(\mathrm{PPh}_{2}\left(\mathrm{C}_{6} \mathrm{H}_{4}-\mathrm{CH}_{2} \mathrm{OH}\right)\right)_{4}\right]$ amorphous
$1 \cdot$ THF

$1 \cdot \mathrm{CH}_{3} \mathrm{CN}$

$1 \mathrm{G}$

1A

\section{Results and Discussion.}

\section{Synthesis and $\mathrm{X}$-ray Diffraction Characterizations.}

$\left[\mathrm{Cu}_{4} \mathrm{I}_{4}\left(\mathrm{PPh}_{2}\left(\mathrm{C}_{6} \mathrm{H}_{4}-\mathrm{CH}_{2} \mathrm{OH}\right)\right)_{4}\right]$ (1) cluster was synthesized in dichloromethane by reacting $\mathrm{CuI}$ and the $\mathrm{PPh}_{2}\left(\mathrm{C}_{6} \mathrm{H}_{4}-\mathrm{CH}_{2} \mathrm{OH}\right)$ phosphine ligand at room temperature. $\mathbf{1} \cdot \mathbf{C H}_{\mathbf{3}} \mathbf{C N}$ was obtained as a colorless crystalline powder by recrystallization in $\mathrm{CH}_{3} \mathrm{CN}$ as previously described in the study of cluster-based organogels. ${ }^{41}$ Recrystallization in a tetrahydrofuran/cyclohexane solvents mixture led to another solvate, 1 THF, as colorless crystals. The AIE (Aggregation Induced Emission) properties of this solvate were previously studied and its mechanochromic luminescence properties were shown but not analyzed. ${ }^{42}$ The structure of the two polymorphs were determined by single-crystal X-Ray diffraction analysis at $150 \mathrm{~K}$, that of $\mathbf{1} \cdot \mathbf{C H}_{3} \mathbf{C N}$ was already reported ${ }^{41}$ but is anew described here for comparison with $\mathbf{1} \cdot \mathbf{T H F}$. The determined formula namely $\left[\mathrm{Cu}_{4} \mathrm{I}_{4}\left(\mathrm{PPh}_{2}\left(\mathrm{C}_{6} \mathrm{H}_{4}-\mathrm{CH}_{2} \mathrm{OH}\right)\right)_{4}\right] \cdot 3 \mathrm{C}_{4} \mathrm{H}_{8} \mathrm{O} \quad(\mathbf{1} \cdot \mathbf{T H F})$ and $\left[\mathrm{Cu}_{4} \mathrm{I}_{4}\left(\mathrm{PPh}_{2}\left(\mathrm{C}_{6} \mathrm{H}_{4}-\mathrm{CH}_{2} \mathrm{OH}\right)\right)_{4}\right]^{\bullet} \mathrm{C}_{2} \mathrm{H}_{3} \mathrm{~N}\left(\mathbf{1} \cdot \mathbf{C H}_{3} \mathbf{C N}\right)$ with in both cases solvent molecules included, were confirmed by liquid ${ }^{1} \mathrm{H}$ NMR and elemental analysis (experimental section in $\mathrm{SI}$ ). The purity of the samples was further confirmed by powder X-Ray diffraction with good matching between the experimental and the calculated powder patterns (Figures 3 and S3).

1 THF and $\mathbf{1} \cdot \mathbf{C H}_{3} \mathbf{C N}$ crystallize in the triclinic $P-1$ space group (Table S1). The unit cells are shown in Figures S1-2. The structures can be described as a 2D arrangement of clusters in the $a, b$ plan, solvent 
molecules being located between the plans. The molecular structure of both clusters are depicted in Figure 1. They present the classical cubane structure with four copper atoms forming a tetrahedron that is included within a larger tetrahedron of the four iodide atoms resulting in a $\left[\mathrm{Cu}_{4} \mathrm{I}_{4}\right]$ distorted cube. The phosphine ligands are coordinated to the copper atoms by the phosphorous and present structural disorder. In 1•THF, one $\mathrm{CH}_{2} \mathrm{OH}$ group is disordered over two positions and in $\mathbf{1} \cdot \mathbf{C} \mathbf{H}_{3} \mathbf{C N}$ three $\mathrm{C}_{6} \mathrm{H}_{4}$ $\mathrm{CH}_{2} \mathrm{OH}$ moieties are concerned. Selected bond distances and angles are reported in Table 1. Overall, the clusters present standard geometric characteristics for copper iodide clusters of cubane geometry coordinated by phosphine ligands. ${ }^{43}$ The mean values of the $\mathrm{Cu}-\mathrm{I}, \mathrm{Cu}-\mathrm{P}$ bond distances and I-Cu-I angles are similar for the two polymorphs. $\mathrm{Cu}-\mathrm{Cu}$ distances are shorter in 1.THF compared with those of $1 \cdot \mathbf{C H}_{3} \mathbf{C N}$ (mean values of 2.900(1) vs 2.942(1) $\AA$ ) leading to a more contracted $\mathrm{Cu}_{4}$ tetrahedron $(2.85(1)$ vs 3.00(1) $\AA^{3}$ ). The $\mathrm{Cu}-\mathrm{Cu}$ distances values are quite close to the $2.80 \AA$ value of the van der Waals radii of $\mathrm{Cu}$, suggesting significant cuprophilic bonding interaction $\left(\mathrm{d}^{10}-\mathrm{d}^{10}\right)$ in both polymorphs. ${ }^{44,45}$ This contrasts with some previously reported mechanochromic copper iodide clusters whose $\mathrm{Cu}-\mathrm{Cu}$ values can reach $3.3 \AA{ }^{35 a, e}$ With shorter $\mathrm{Cu}-\mathrm{Cu}$ distances and comparable $\mathrm{Cu}-\mathrm{I}$ bonds, $\mathbf{1}$-THF presents a more distorted $\left[\mathrm{Cu}_{4} \mathrm{I}_{4}\right]$ cluster core with a much larger standard deviation of the I-Cu-I angles values (3.4 vs $1.5^{\circ}$ ) compared with the more symmetrical cluster core of $\mathbf{1} \cdot \mathbf{C H} \mathbf{H}_{3} \mathbf{C N}$.
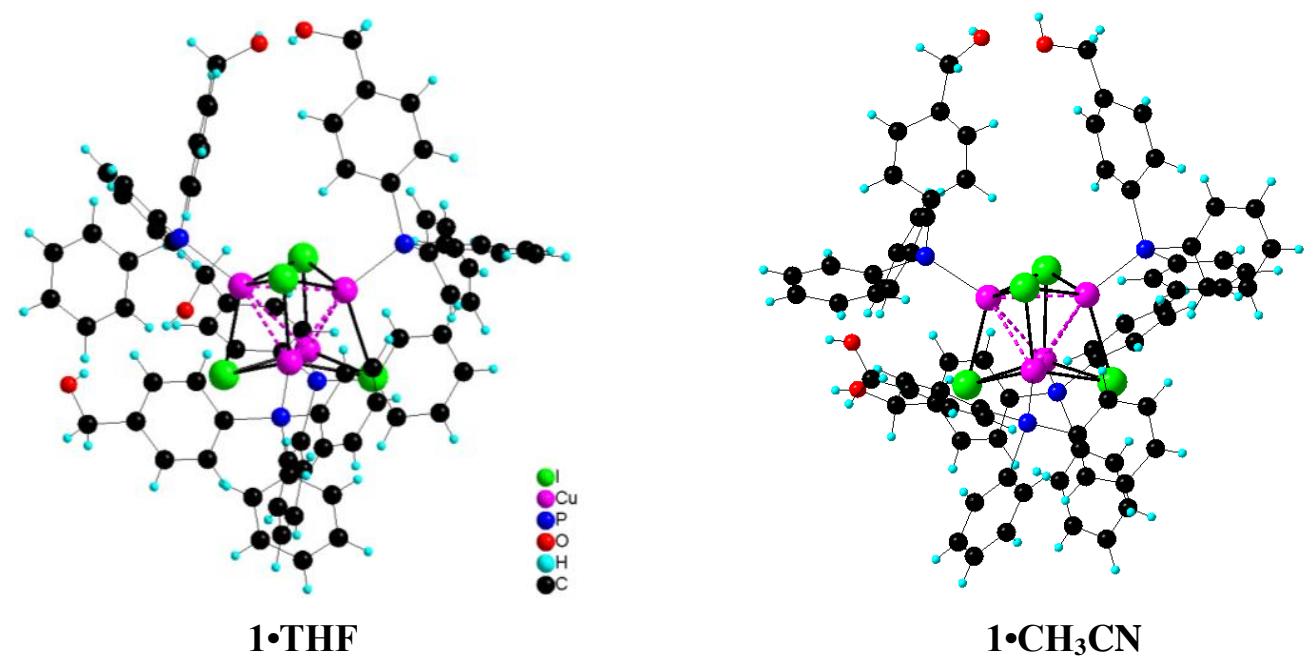

Figure 1. Molecular structure of $\left[\mathrm{Cu}_{4} \mathrm{I}_{4}\left(\mathrm{PPh}_{2}\left(\mathrm{C}_{6} \mathrm{H}_{4}-\mathrm{CH}_{2} \mathrm{OH}\right)_{4}\right]\right.$ cluster in $\mathbf{1} \cdot \mathbf{T H F}$ and $\mathbf{1} \cdot \mathbf{C} \mathbf{C H}_{3} \mathbf{C N}$. Structural disorder of the ligands is not shown for clarity. $\mathrm{Cu}-\mathrm{Cu}$ contacts are represented in dashed pink lines.

Table 1. Selected bonds lengths and angles of $\left[\mathrm{Cu}_{4} \mathrm{I}_{4}\left(\mathrm{PPh}_{2}\left(\mathrm{C}_{6} \mathrm{H}_{4}-\mathrm{CH}_{2} \mathrm{OH}\right)_{4}\right]\right.$ cluster in $\mathbf{1} \cdot \mathbf{T H F}$ and $\mathbf{1} \cdot \mathbf{C H}_{3} \mathbf{C N}$ from SCXRD data recorded at $150 \mathrm{~K}$.

\begin{tabular}{|c|c|c|}
\hline & $\mathbf{1} \mathbf{T H F}$ & $\mathbf{1}^{-C_{H}} \mathbf{C N}$ \\
\hline $\mathbf{C u}-\mathbf{C u}(\AA)$ & $2.7636(12) 2.7777(12)$ & $2.9016(10) 2.9120(9)$ \\
& $2.8411(12) 2.9044(12)$ & $2.9226(10) 2.9400(9)$ \\
mean & $3.0262(12) 3.0855(12)$ & $2.9668(10) 3.0067(9)$ \\
standard-deviation & $2.8998(12)$ & $2.9416(10)$ \\
$\mathbf{C u} 4\left(\AA^{3}\right)$ & 0.132 & 0.039 \\
& $2.85(1)$ & $3.00(1)$ \\
\hline
\end{tabular}




\begin{tabular}{|c|c|c|}
\hline $\begin{array}{c}\mathbf{C u}-\mathbf{I}(\AA) \\
\\
\text { mean } \\
\text { standard-deviation }\end{array}$ & $\begin{array}{c}2.6542(10) 2.6629(10) \\
2.6845(10) 2.6815(10) \\
2.6924(11) 2.7036(10) \\
2.6722(10) 2.6760(10) \\
2.7221(10) 2.6782(10) \\
2.6884(10) 2.7100(10) \\
2.6855(10) \\
0.019\end{array}$ & $\begin{array}{c}2.6429(7) 2.6657(8) \\
2.6694(9) 2.6716(8) \\
2.6822(7) 2.6830(8) \\
2.6921(8) 2.6957(7) \\
2.6982(7) 2.7030(8) \\
2.7080(8) 2.7465(8) \\
2.6882(9) \\
0.026\end{array}$ \\
\hline $\begin{array}{c}\mathbf{C u}-\mathbf{P}(\AA) \\
\\
\text { mean } \\
\text { standard-deviation }\end{array}$ & $\begin{array}{l}2.2532(19) \\
2.2623(19) \\
2.2512(18) \\
2.2540(20) \\
2.2552(19) \\
0.005\end{array}$ & $\begin{array}{c}2.2555(14) \\
2.2574(17) \\
2.2577(14) \\
2.2640(14) \\
2.2587(17) \\
0.004\end{array}$ \\
\hline $\begin{array}{c}\text { mean } \\
\text { standard-deviation }\end{array}$ & $\begin{array}{c}113.98(4) 110.24(3) \\
105.39(4) 111.48(3) \\
112.15(3) 109.92(3) \\
110.91(3) 106.45(3) \\
104.49(3) 114.61(3) \\
111.65(3) 105.94(3) \\
109.77(3) \\
3.405\end{array}$ & $\begin{array}{c}107.42(2) 107.50(3) \\
107.93(2) 108.25(2) \\
108.42(3) 108.92(3) \\
109.18(3) 109.63(2) \\
109.88(3) 110.40(3) \\
110.72(2) 112.37(3) \\
109.22(3) \\
1.468\end{array}$ \\
\hline
\end{tabular}

Occurrence of alcohol function on the ligand leads to the formation of hydrogen bonds within the structures (Figures S1-2). Short $\mathrm{O} \cdots \mathrm{O}$ contacts $\left(<3 \AA\right.$ ) occur between the $\mathrm{CH}_{2} \mathrm{OH}$ groups with one intramolecular of 2.743(1) and 2.579(1) $\AA$ for $\mathbf{1} \cdot \mathbf{T H F}$ and $\mathbf{1} \cdot \mathbf{C} \mathbf{H}_{3} \mathbf{C N}$, respectively. Several others are

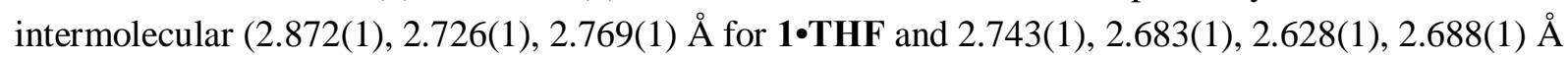
for $\mathbf{1} \cdot \mathbf{C H}_{3} \mathbf{C N}$ ), which connect the clusters along the $c$ axis. In $\mathbf{1} \cdot \mathbf{T H F}$ another hydrogen bond implies one THF solvent molecule (2.799(1) A, Figure S1).

In order to support the different analysis performed to characterize the mechanochromic properties of the studied cluster, DFT calculations were carried out with Gaussian. ${ }^{46}$ The PBE0 functional and a standard double- $\xi$ polarized basis set (LANL2DZ), were used augmented with polarization functions on all atoms. ${ }^{47,48}$ For the cluster structure optimization, the molecular structure of $\mathbf{1} \cdot \mathbf{T H F}$ was used as the starting point. Using the structure of $\mathbf{1} \cdot \mathbf{C H}_{3} \mathbf{C N}$ led to a similar optimized structure. All structures were optimized and checked to be at the minimum of the potential energy surface with frequency calculations. Since the cluster structure is too large to perform anharmonic computations, harmonic IR and Raman spectra were simulated and corrected with a scaling factor of 0.96 . For calculations of the NMR parameters and ${ }^{63} \mathrm{Cu}$ solid-state spectra simulations, the DEF2TZVP basis set was enforced upon relaxation with the same functional. The UV-visible absorption transitions were calculated by TD-DFT (time dependent-DFT) calculations ${ }^{49}$ and spin-unrestricted method was used to perform computations of the excited states. To simulate the phosphorescence spectra, vibronic contributions to electronic transitions were modelled using the Vertical Hessian approach as implemented in the version of the Gaussian Package. The VMS software was used for all data post-treatments. ${ }^{50}$ More details are given in SI.

\section{Mechanochromic properties.}

1 $\mathbf{T H F}$ and $\mathbf{1} \cdot \mathrm{CH}_{\mathbf{3}} \mathbf{C N}$ are both photoluminescent and display bright green emission under UV excitation at room temperature. Upon manual grinding in a mortar, they demonstrate substantial emission color changes from green to yellow without modification of the colorless body-color (Figure 2). These 
luminescence mechanochromic properties of the polymorphs were then characterized. Since their ground phases present similar properties $\left({ }^{1} \mathrm{H}\right.$ and ${ }^{31} \mathrm{P}$ liquid NMR, luminescence spectra and PXRD patterns in Figure S3), only results regarding the ground phase of 1•THF (1G) are detailed in the following for clarity reasons. Reversibility of the mechanochromism occurs upon THF vapor exposure (other solvents were tried without success), which induces recrystallization of the compound (emission spectra and PXRD patterns in Figure S4) but is not observed upon thermal treatment.
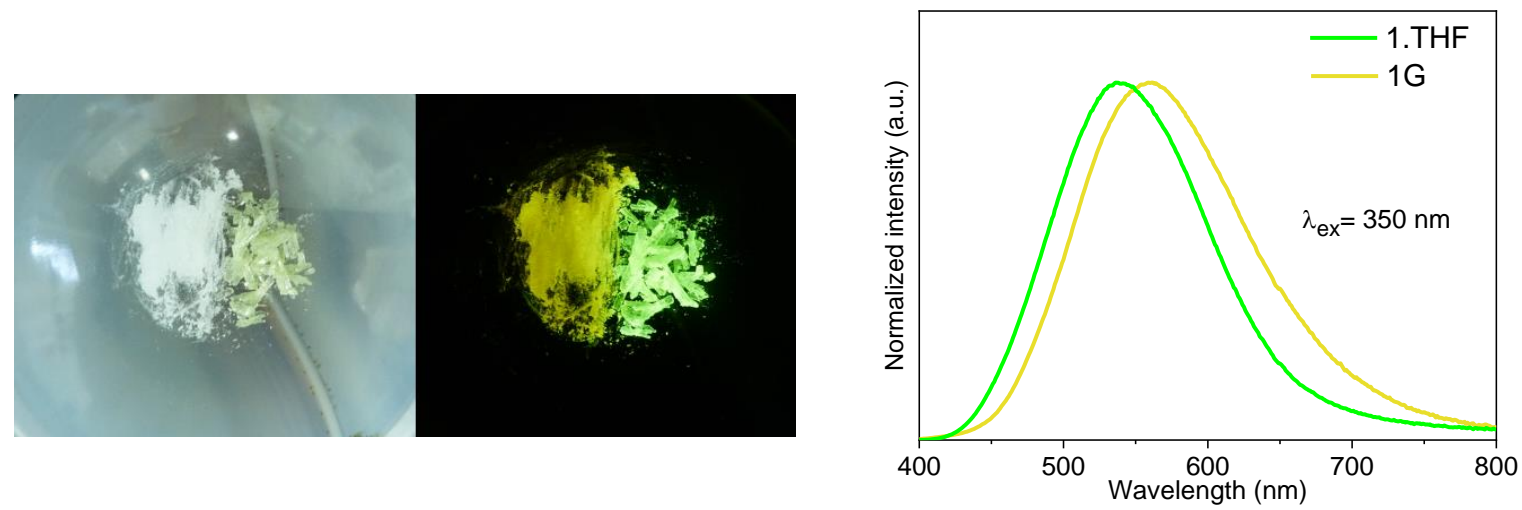

Figure 2. Photos of partially ground crystals (left side) of 1.THF under visible light and UV irradiation ( $365 \mathrm{~nm}$ lamp), at room temperature and corresponding emission spectra.

Elemental analyses of $\mathbf{1}$ THF before and after grinding (1G) revealed the same chemical composition and a partial loss of the THF solvent molecules (experimental section in SI). This result indicates the preservation of the $\left[\mathrm{Cu}_{4} \mathrm{I}_{4}\left(\mathrm{PPh}_{2}\left(\mathrm{C}_{6} \mathrm{H}_{4}-\mathrm{CH}_{2} \mathrm{OH}\right)_{4}\right]\right.$ cluster after grinding and that no chemical reaction occurs which is confirmed by similar ${ }^{1} \mathrm{H}$ and ${ }^{31} \mathrm{P}$ liquid NMR spectra before and after grinding (experimental section in SI). From TGA-DSC (Figure S5), ${ }^{1} \mathrm{H}$ liquid NMR and elemental analysis of 1G, around two over the three solvent molecules have left the structure during the grinding process. If powder of 1.THF is placed under vacuum for 1h30, no solvent loss is observed (TGA-DSC in Figure S5 and ${ }^{1} \mathrm{H}$ NMR analysis). This means that the solvent departure is triggered by the mechanical solicitations. However, because the two polymorphs $\mathbf{1} \cdot \mathbf{T H F}$ and $\mathbf{1} \cdot \mathbf{C H}_{3} \mathbf{C N}$ including different solvent, display similar luminescence properties, we can assume that solvent departure is not responsible for the luminescence changes. The solvent generates different crystalline structures but it is not directly involved in the emission mechanism. The powder X-ray diffraction (PXRD) analysis of 1G shows that the well resolved diffraction peaks of the pristine phase, are broadened after grinding (Figure 3). This clearly indicates alteration of the crystalline structure by the mechanical solicitation with partial amorphization. 


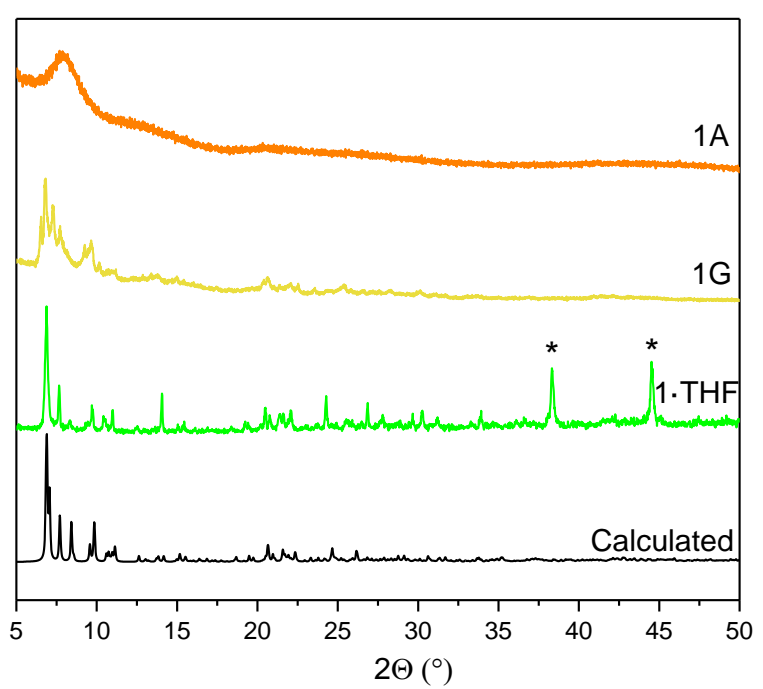

Figure 3. PXRD patterns of 1•THF, 1G and 1A along with theoretical diagram calculated from the SCXRD data.*sample holder (Al).

Because a crystalline-to-amorphous transition occurs, we explored the possibility to obtain a totally amorphous phase. TGA DSC analysis of $\mathbf{1}$ THF showed a first endothermic peak around $140{ }^{\circ} \mathrm{C}$ related to solvent departure, followed by second one at $230{ }^{\circ} \mathrm{C}$ corresponding to a melting transition (Figure S5). No exothermic peak is observed upon cooling down indicating no possible recrystallization. Similar DSC curve is observed for $\mathbf{1 G}$, in accordance with mechanochromism irreversibility upon thermal treatment. Crystalline powder of $\mathbf{1} \mathbf{T H F}$ was then heated at $225^{\circ} \mathrm{C}$ under inert atmosphere and melting was observed leading, after rapid cooling (melt quenching), to the amorphous phase (1A). Elemental analysis and liquid NMR $\left({ }^{1} \mathrm{H}\right.$ and $\left.{ }^{31} \mathrm{P}\right)$ confirmed the integrity of the cluster in $\mathbf{1 A}$ and the total loss of the THF solvent molecule (experimental section in SI). The PXRD pattern of 1A presents a very broad peak around $7^{\circ}$ attesting its amorphous state (Figure 3). To our knowledge, this is the first reported amorphous phase for such copper iodide cluster.

In order to identify local transformations induced by the grinding effect, solid-state NMR analysis were performed on 1•THF, 1•C $\mathbf{H}_{3} \mathbf{C N}, \mathbf{1 G}$ and $\mathbf{1 A} .{ }^{1} \mathrm{H}$ and ${ }^{13} \mathrm{C}$ magic-angle spinning (MAS) NMR spectra are in agreement with the $\mathrm{PPh}_{2}\left(\mathrm{C}_{6} \mathrm{H}_{4}-\mathrm{CH}_{2} \mathrm{OH}\right)$ ligand (Figure S6). The ${ }^{1} \mathrm{H}$ spectra all show signals of the phenyl groups at $\sim 8 \mathrm{ppm}$. For 1 $\mathbf{\bullet T H F}$ and $\mathbf{1 G}$ signals of the THF solvent molecules are observed at $\sim$ 3 and $1 \mathrm{ppm}$. For $\mathbf{1} \cdot \mathrm{CH}_{3} \mathbf{C N}$, the weak signal of the $\mathrm{CH}_{3} \mathrm{CN}$ molecule is observed at $\sim 2 \mathrm{ppm}$. As expected, the signal of the phenyl groups is predominantly observed for the $\mathbf{1 A}$ solvent free phase. The signal of the $\mathrm{OH}$ group of the methanol moiety, too broad, is not observed and that of the $\mathrm{CH}_{2}$ group can be guessed at around $2 \mathrm{ppm}$. For all compounds, the main ${ }^{13} \mathrm{C}$ NMR peaks correspond to the phenyl groups of the ligands (140-110 ppm) and to the $\mathrm{CH}_{2}$ group ( $\sim 57 \mathrm{ppm}$ ). More broadened peaks are clearly observed for $\mathbf{1 A}$ that could be due either to its amorphous character or to dynamics of the monitored domains.

${ }^{63} \mathrm{Cu}$ static and ${ }^{31} \mathrm{P}$ MAS NMR spectra are shown in Figure 4 . The ${ }^{63} \mathrm{Cu}$ nucleus has a large quadrupolar moment giving rise to particularly broad static NMR spectra for which the individual components are not resolved. Similar ${ }^{63} \mathrm{Cu}$ patterns are observed for $\mathbf{1} \cdot \mathbf{T H F}, \mathbf{1} \cdot \mathbf{C H}_{3} \mathbf{C N}, \mathbf{1 G}$ and $\mathbf{1 A}$, whose features 
(span and shape of the static pattern) are characteristic of the $\left[\mathrm{Cu}_{4} \mathrm{I}_{4}\right]$ cubane structure. ${ }^{51,52}$ This is confirmed by the ${ }^{63} \mathrm{Cu}$ NMR parameters of $\mathbf{1}$ THHF calculated at the DFT level from the structural model, that reproduces well the observed NMR spectrum (Figure S7 and Table S2). This result confirms once more the preservation of the cubane cluster $\left[\mathrm{Cu}_{4} \mathrm{I}_{4}\left(\mathrm{PPh}_{2}\left(\mathrm{C}_{6} \mathrm{H}_{4}-\mathrm{CH}_{2} \mathrm{OH}\right)_{4}\right]\right.$ within the $\mathbf{1 G}$ and $\mathbf{1 A}$ phases. The ${ }^{31} \mathrm{P}$ MAS spectrum of $\mathbf{1} \cdot \mathbf{T H F}$ presents multiple peaks resulting from the one-bond $J$-couplings between the ${ }^{31} \mathrm{P}$ atoms and the two copper isotopes $\left({ }^{65} \mathrm{Cu}\right.$ and ${ }^{63} \mathrm{Cu}$ of $3 / 2$ nuclear spin with 30.8 and 69.2 $\%$ of natural abundance, respectively), leading to two quartets. ${ }^{53}$ Therefore, with four independent phosphorus sites in 1.THF, eight quartets are expected with high overlapping (this is similar for $\mathbf{1} \cdot \mathbf{C H}_{3} \mathbf{C N}$ ). As shown earlier, a ${ }^{13} \mathrm{P}_{-}{ }^{63} \mathrm{Cu}$ heteronuclear multiple quantum (HMQC) filter ${ }^{54}$ can be applied to filter out the ${ }^{31} \mathrm{P}_{-}{ }^{65} \mathrm{Cu} \mathrm{J}$-multiplets, greatly simplifying the spectrum analysis. ${ }^{55}$ From such a simplified spectrum, the number of resonances, isotropic chemical shifts $\left(\delta_{\text {iso }}\right)$ and $J$-coupling constants can be easily determined (Figure S8-11). Both polymorphs exhibit two inequivalent ${ }^{31} \mathrm{P}$ NMR resonances: the two lines of similar intensity in $\mathbf{1} \cdot \mathbf{T H F}$ are located at $\delta_{\text {iso }}=-23.2 \mathrm{ppm}\left({ }^{1} \mathrm{~J}^{31 \mathrm{P}-63 \mathrm{Cu}}=1510 \mathrm{~Hz}\right)$ and $\delta_{\text {iso }}=-$ $26.0 \mathrm{ppm}\left({ }^{1} J^{31 \mathrm{P}-63 \mathrm{Cu}}=1485 \mathrm{~Hz}\right)$, while the two lines of relative intensity $3: 1 \mathrm{in} \mathbf{1} \cdot \mathbf{C} \mathbf{H}_{\mathbf{3}} \mathbf{C N}$ are located at $\delta_{\text {iso }}=-20.7 \mathrm{ppm}\left({ }^{1} J^{31 \mathrm{P}-63 \mathrm{Cu}}=1587 \mathrm{~Hz}\right)$ and $\delta_{\text {iso }}=-30.6 \mathrm{ppm}\left({ }^{1} J^{31 \mathrm{P}-63 \mathrm{Cu}}=1630 \mathrm{~Hz}\right)$, in accordance with the different geometry and symmetry of their molecular structures. Indeed, while $\mathrm{Cu}-\mathrm{P}$ and $\mathrm{Cu}-\mathrm{I}$ bond distances are quite similar, the $\mathrm{Cu}-\mathrm{Cu}$ interactions are clearly distinct with a more symmetrical cluster core for $\mathbf{1}^{\cdot} \mathbf{C H}_{3} \mathbf{C N}$. The DFT calculations further confirm the similarity of the ${ }^{31} \mathrm{P} \delta_{\text {iso }}$ for pairs of phosphorus atoms in $\mathbf{1}$ THF (Table S2). This result shows the sensitivity of the ${ }^{31} \mathrm{P}$ NMR MAS analysis to detect relatively small structural changes. The ${ }^{31} \mathrm{P}$ NMR spectra of $\mathbf{1 G}$ presents similar structure to that of pristine phase with little shift and a broadening of the peaks. The additional broad signal suggests amorphization of the compound and modification of the phosphorous environment induced by the grinding. This effect is clearly more pronounced for the amorphous phase $\mathbf{1 A}$ with even broader ${ }^{31} \mathrm{P}$ signal shifted to higher magnetic field (barycentre of the resonance is at $-18.8 \mathrm{ppm}$, Figure 4), for which the $J$-coupling patterns can no longer be seen. However, they are still present as attested by the HMQC NMR spectrum (Figure S11, in the absence of Cu-P J-coupling, there would be no signal at all on the HMQC NMR spectrum), which is narrower than the ${ }^{31} \mathrm{P}$ NMR spectrum due to the removal of the ${ }^{31} \mathrm{P}-$ ${ }^{65} \mathrm{Cu} J$-multiplets. The presence of $J$-multiplets confirms the preservation of the cluster-phosphine bonds in the amorphous phase. Looking in details at the ${ }^{31} \mathrm{P}$ spectrum of $\mathbf{1 G}$, it can be noticed that it is the sum of signals coming from the two narrow peaks of the crystalline phase 1.THF and of the broad signal from the amorphous phase 1A, in agreement with PXRD analysis. Deconvolution of the spectrum of 1G (Figure 5) shows that both resonances of the pristine phase still have similar intensity, indicating that the grinding affects the cluster homogeneously. From this analysis, it is also possible to quantify the amount of amorphous phase within 1G, which is evaluated to $25 \%$. This analysis is very informative for the mechanochromism mechanism and was facilitated by the data obtained for the amorphous $\mathbf{1 A}$ phase. It therefore allows to state that the grinding process induces partial amorphization of the compound while keeping intact $75 \%$ of the crystalline phase. 


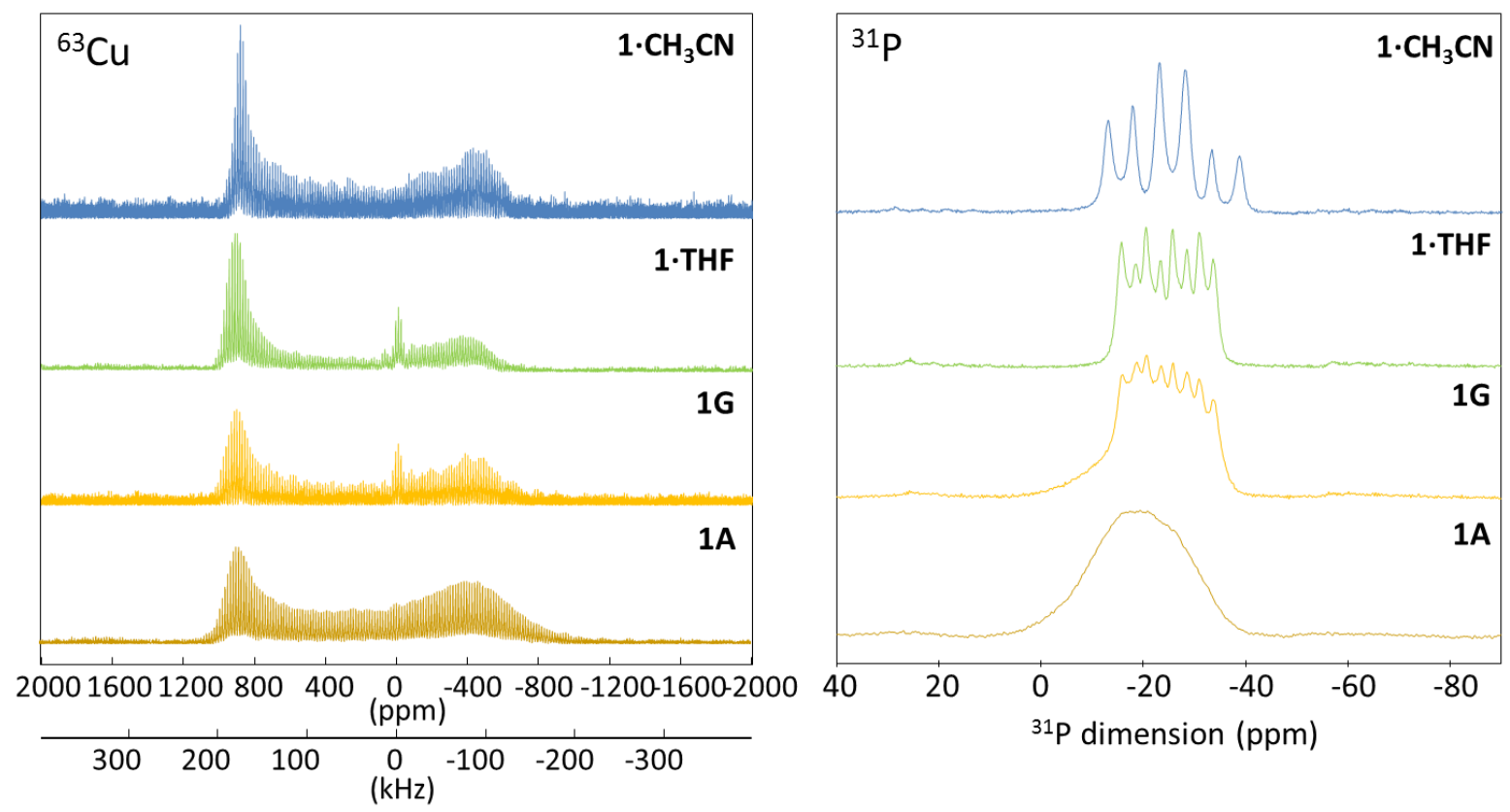

Figure 4. Solid-state NMR ${ }^{63} \mathrm{Cu}$ static WURST-QCPMG spectra and ${ }^{31} \mathrm{P}$ CPMAS spectra of $\mathbf{1} \cdot \mathbf{C H}_{3} \mathbf{C N}, \mathbf{1} \cdot \mathbf{T H F}$, $1 \mathbf{G}$ and $1 \mathrm{~A}$. The peaks at $0 \mathrm{ppm}$ in $\mathbf{1} \mathbf{T H F}$ and $\mathbf{1 G}$ are attributed to artefacts from the experiment.

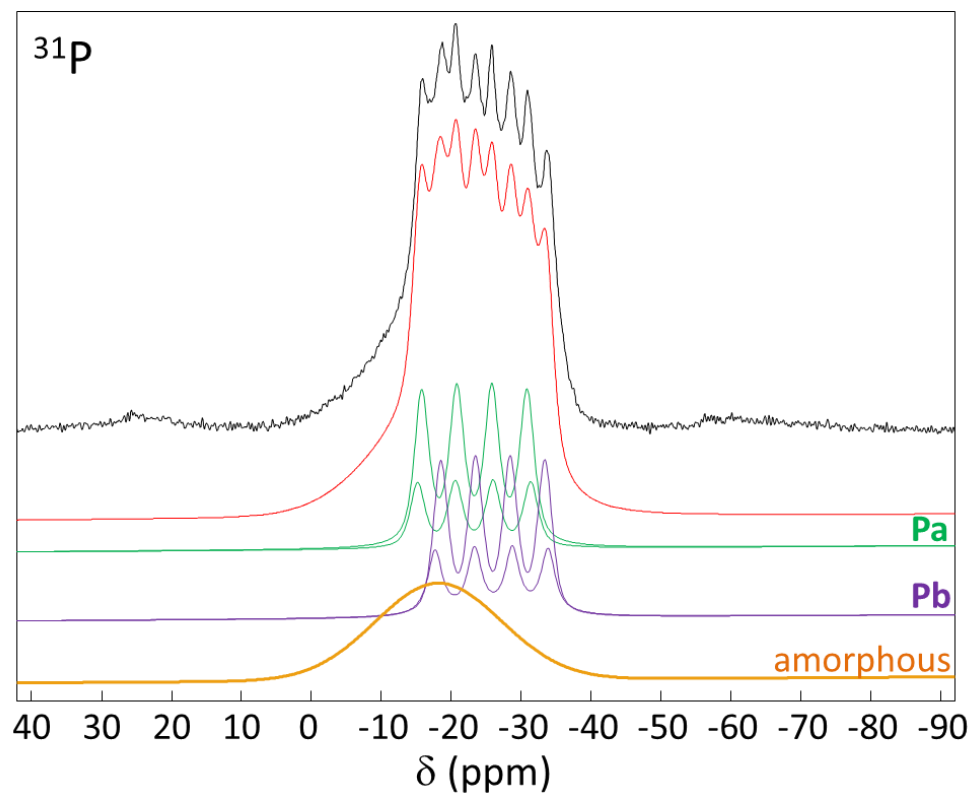

Figure 5. Deconvolution of the ${ }^{31} \mathrm{P}$ spectrum of 1G. The crystalline contribution contains two ${ }^{31} \mathrm{P}$ resonances labelled $\mathrm{Pa}$ and $\mathrm{Pb}$, each of them being the sum of two quartet resulting from the ${ }^{31} \mathrm{P}_{-}{ }^{63} \mathrm{Cu}$ and ${ }^{31} \mathrm{P}-{ }^{65} \mathrm{Cu} J$-couplings. The amorphous contribution was simulated using a Gaussian line shape, according to the shape of the ${ }^{31} \mathrm{P}$ NMR spectrum of $\mathbf{1 A}$.

All compounds were characterized by IR and Raman analysis and the spectra of $\mathbf{1} \mathbf{T H F}$ were simulated by DFT calculations. A good agreement is observed between the experimental and the simulated vibrational signatures allowing a possible assignment of the vibrational bands (Figure S12). The main bands were assigned to the dominant involved vibrations (Table S3). Precisely assign the vibrational 
bands is complex due to the entangled and coupled movements in such high nuclearity compounds, therefore assignment must be taken with some caution. In Figure 6 are reported the experimental IR spectra of 1•THF, $\mathbf{1} \cdot \mathbf{C H}_{3} \mathbf{C N}, \mathbf{1 G}$ and $\mathbf{1 A}$ from 45 to $4000 \mathrm{~cm}^{-1}$. Low frequencies region was explored $\left(45-650 \mathrm{~cm}^{-1}\right)$ because the vibrational bands involving the $\left[\mathrm{Cu}_{4} \mathrm{I}_{4}\right]$ cluster core are expected in this range. Below $450 \mathrm{~cm}^{-1}$, all vibrations are attributed to the $\mathrm{PPh}_{2}\left(\mathrm{C}_{6} \mathrm{H}_{4}-\mathrm{CH}_{2} \mathrm{OH}\right)$ ligand. More specifically, the frequencies at $836 \mathrm{~cm}^{-1}$ and $1478 \mathrm{~cm}^{-1}$ come from the phenyl groups. The two bands observed at 2920 $\mathrm{cm}^{-1}$ and $2967 \mathrm{~cm}^{-1}$ are related to stretching of the $\mathrm{CH}_{2}$ units. The large band over the $3100-3500 \mathrm{~cm}^{-1}$ range correspond to the $\mathrm{OH}$ groups (stretching) which are involved in hydrogen bonds. Such interactions effectively occur within the crystalline structure as previously described. In the $45-650 \mathrm{~cm}^{-1}$ range, the two first bands at $87 \mathrm{~cm}^{-1}$ (Cu-I stretching) and $125 \mathrm{~cm}^{-1}$ (Cu-I stretching and $\mathrm{Cu}-\mathrm{Cu}$ breathing) in the 1.THF spectra, imply the $\left[\mathrm{Cu}_{4} \mathrm{I}_{4}\right]$ cluster core. These results are in accordance with previous studies on IR analysis of phosphine-based $\left[\mathrm{Cu}_{4} \mathrm{I}_{4} \mathrm{~L}_{4}\right]$ clusters reporting two characteristic bands of the cubane structure at around 90 and $140 \mathrm{~cm}^{-1}$ involving $\mathrm{Cu}-\mathrm{I}$ vibrations. ${ }^{56,57,58}$ The two bands observed at 258 and $287 \mathrm{~cm}^{-1}$ are assigned to $\mathrm{Cu}-\mathrm{P}$ stretching vibrations. The bands at 383 and $396 \mathrm{~cm}^{-1}$ involve the phosphine ligands ( $\mathrm{C}-\mathrm{H}$ bonds). The intense peaks in the range $469-516 \mathrm{~cm}^{-1}$ correspond to combinations of $\mathrm{Cu}-\mathrm{P}$ and $\mathrm{P}-\mathrm{C}$ vibrations.
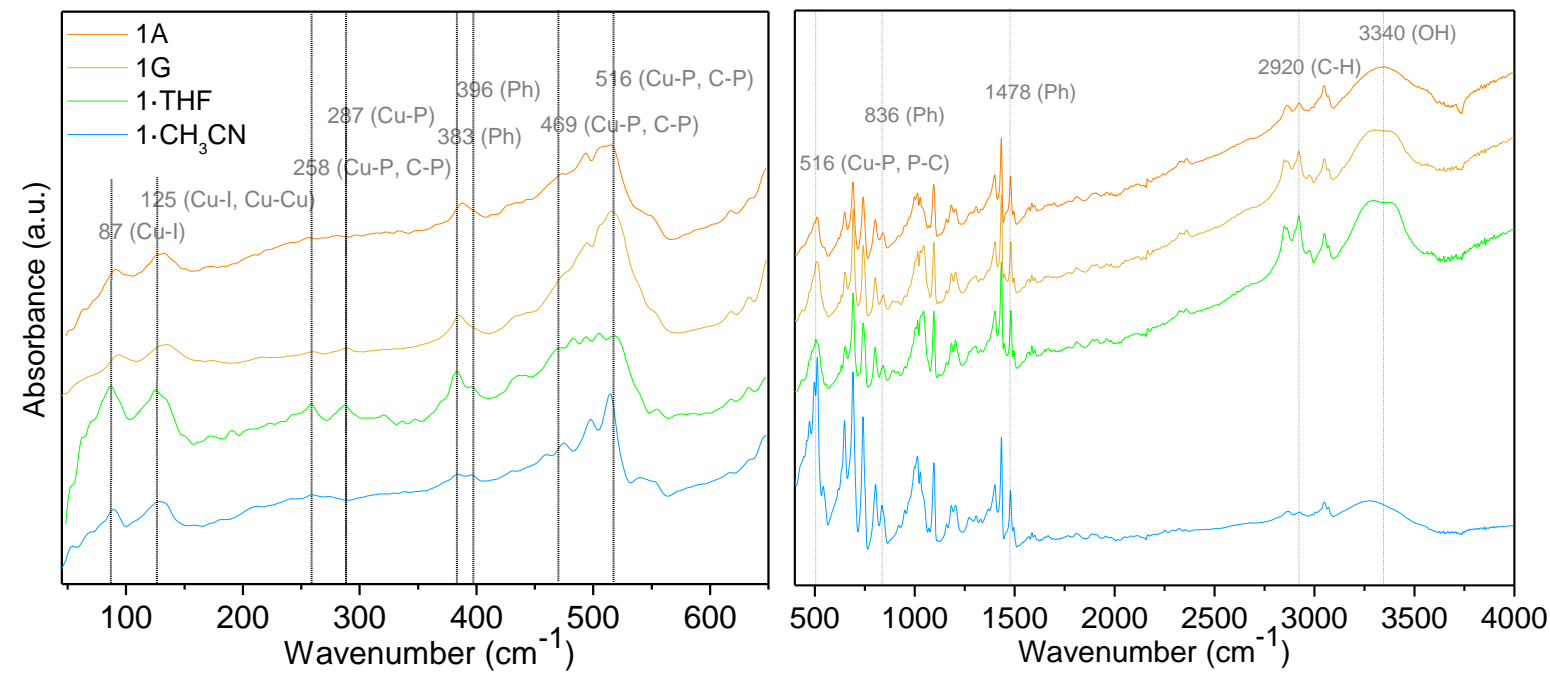

Figure 6. IR spectra of $\mathbf{1} \cdot \mathbf{T H F}, \mathbf{1} \cdot \mathbf{C H}_{3} \mathbf{C N}, \mathbf{1 G}$ and $\mathbf{1 A}$ in the $45-650$ and $450-4000 \mathrm{~cm}^{-1}$ regions.

Comparison of the four spectra indicates an overall similar signature, in accordance with their common molecular component (Figure 6). In the $450-4000 \mathrm{~cm}^{-1}$ region, the four similar spectra agree with no significant modification of the ligand. However, the large band centered at $3300 \mathrm{~cm}^{-1}$ exhibits different feature. 1G presents a slightly larger band compared with that of 1•THF and this broadening is even larger for $\mathbf{1 A}$ and $\mathbf{1} \cdot \mathbf{C H}_{3} \mathbf{C N}$. This suggests dissimilar hydrogen bonds networks within the different phases. In contrast to previous region, in the low energy region, larger differences are observed between the compounds. By comparing the spectra of $1 \cdot \mathbf{T H F}$ and $\mathbf{1} \cdot \mathbf{C H}_{3} \mathbf{C N}$, a small wavenumber shift is observed from 87 to $89 \mathrm{~cm}^{-1}$ and from 125 to $129 \mathrm{~cm}^{-1}$, in agreement with the different cluster core geometries. Frequencies in the $469-516 \mathrm{~cm}^{-1}$ range are also modified probably due to the different structural arrangements of the phenyl groups. Spectra of $\mathbf{1 G}$ and $\mathbf{1 A}$ are relatively similar with bands at 91 and $133 \mathrm{~cm}^{-1}$. These values are close to those of $\mathbf{1} \cdot \mathbf{C} \mathbf{H}_{3} \mathbf{C N}$, that possibly indicates a more symmetrical $\left[\mathrm{Cu}_{4} \mathrm{I}_{4}\right]$ cluster core in the amorphous phases compared with that of $\mathbf{1} \cdot \mathbf{T H F}$. Modification 
of the vibrations in the $469-516 \mathrm{~cm}^{-1}$ range and disappearance of the bands at 258 and $287 \mathrm{~cm}^{-1}$ of 1 THF, also indicate changes of the $\mathrm{Cu}-\mathrm{P}$ bonds. These results agree with the ${ }^{31} \mathrm{P}$ solid-state NMR analysis showing modification of the phosphorous environment in $\mathbf{1 G}$ and $\mathbf{1 A}$. With the main changes observed in the low frequencies region, IR analyses clearly indicate modifications of the structure of the $\left[\mathrm{Cu}_{4} \mathrm{I}_{4}\right]$ cluster core in the amorphous phases either created by mechanical solicitation or melting. The mechanical solicitations thus essentially impact the cluster core and conversely, the ligand is less affected. This can be explained by the stronger covalent bonds in the ligand, compared with the ionic $\mathrm{Cu}-\mathrm{I}$ and cuprophilic $\mathrm{Cu}-\mathrm{Cu}$ interactions of the cluster core.

Raman spectra from 45 to $3500 \mathrm{~cm}^{-1}$ are shown in Figure 7. Spectra in the $600-3500 \mathrm{~cm}^{-1}$ region are similar for all the compounds and correspond to the phosphine ligand, in accordance with the IR analyses (Table S3). In the low frequencies region, the three bands at 72, 92 and $117 \mathrm{~cm}^{-1}$ in the $\mathbf{1}$.THF spectra are attributed to normal modes of $\mathrm{Cu}-\mathrm{I}$ stretching. The band at $117 \mathrm{~cm}^{-1}$ additionally involves $\mathrm{Cu}-\mathrm{Cu}$ vibrations (breathing). The less intense peaks at $220 \mathrm{~cm}^{-1}$ can be assigned to the $\mathrm{Cu}-\mathrm{P}$ stretching. These results are in agreement with previous experimental data on cubane clusters. ${ }^{56,57,58}$ While the band at 117 $\mathrm{cm}^{-1}$ seems to be similar for both polymorphs, the two other bands are broadened and shifted from 72 to 80 and from 92 to $94 \mathrm{~cm}^{-1}$ for $\mathbf{1} \cdot \mathbf{C H}_{3} \mathbf{C N}$. This agrees with their different molecular structures and $\left[\mathrm{Cu}_{4} \mathrm{I}_{4}\right]$ cluster cores and confirms the IR results. Spectra of $\mathbf{1 A}$ shows a very broad signal with hardly discernible peaks attributed to its disordered amorphous state. Spectra of $\mathbf{1 G}$ is similar to that of $\mathbf{1}$ THF that can be therefore easily explained by the 'invisibility' of its amorphous ground phase and the dominant intact crystalline part. In that case, Raman analysis is clearly less informative compared with IR for studying the mechanochromic effect.
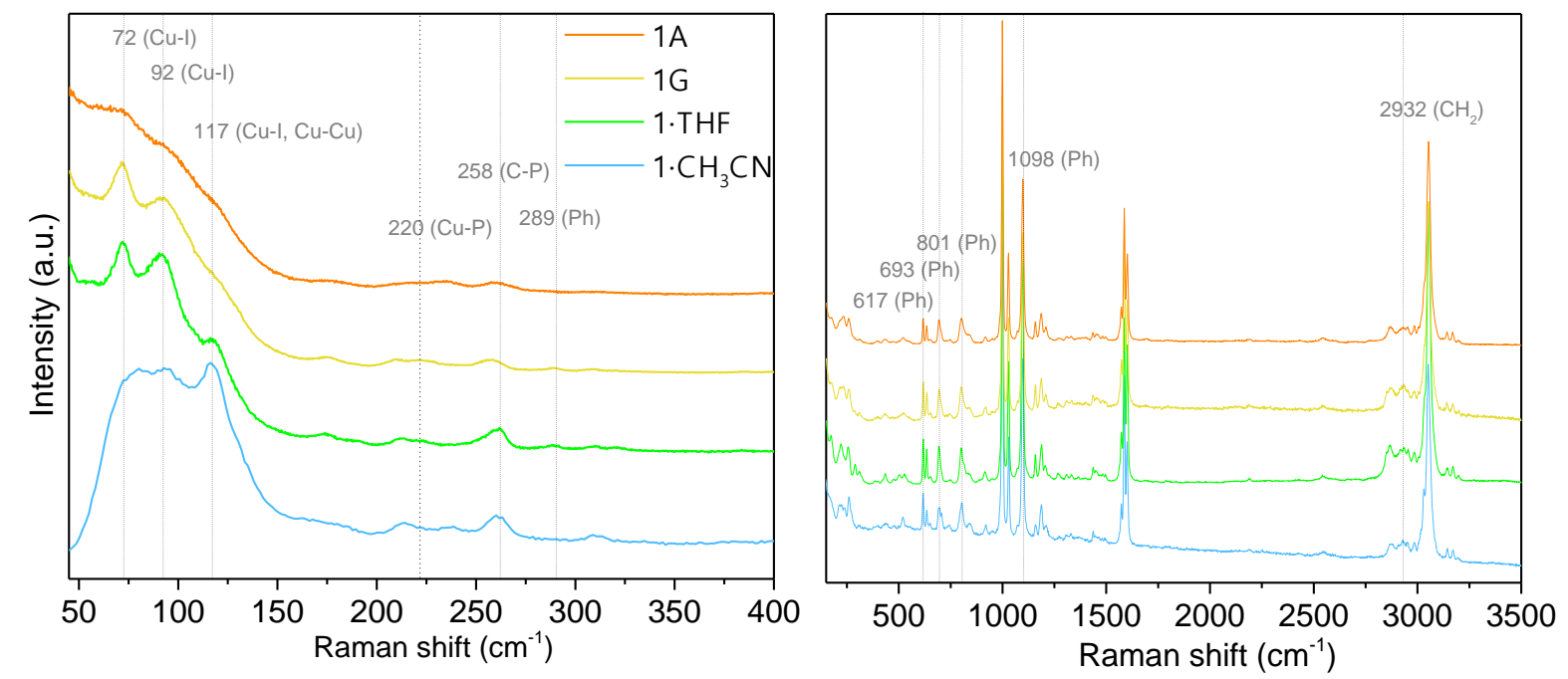

Figure 7. Raman spectra of $1 \cdot \mathrm{THF}, 1 \cdot \mathrm{CH}_{3} \mathrm{CN}, 1 \mathrm{G}$ and $1 \mathrm{~A}$.

\section{Photophysical properties.}

Photos of the samples are gather in Figure 8. While the colorless crystalline $\mathbf{1} \cdot \mathbf{T H F}$ and $\mathbf{1} \cdot \mathbf{C H}_{\mathbf{3}} \mathbf{C N}$ compounds emit an intense green light under UV irradiation at room temperature, the white powder of $\mathbf{1 G}$ and the transparent sample of $\mathbf{1 A}$ present a yellow emission. In opposite to the three other compounds, 1A has a yellow body-color under ambient light. In addition to luminescence mechanochromism, 1 $\mathbf{T H F}$ and $\mathbf{1} \cdot \mathbf{C H}_{\mathbf{3}} \mathbf{C N}$ present thermochromic luminescent properties. Indeed, when placed in liquid nitrogen $(77 \mathrm{~K})$, their green emission becomes turquoise and blue, respectively (Figure 8). The grinding process affects the thermochromic luminescence properties as well since 1G exhibits a 
bright blue emission at $77 \mathrm{~K}$. This is different for $\mathbf{1 A}$ which presents a greener emission by lowering the temperature. Upon progressive warming, the initial emissions are recovered, indicating reversible luminescence thermochromism for the compounds.

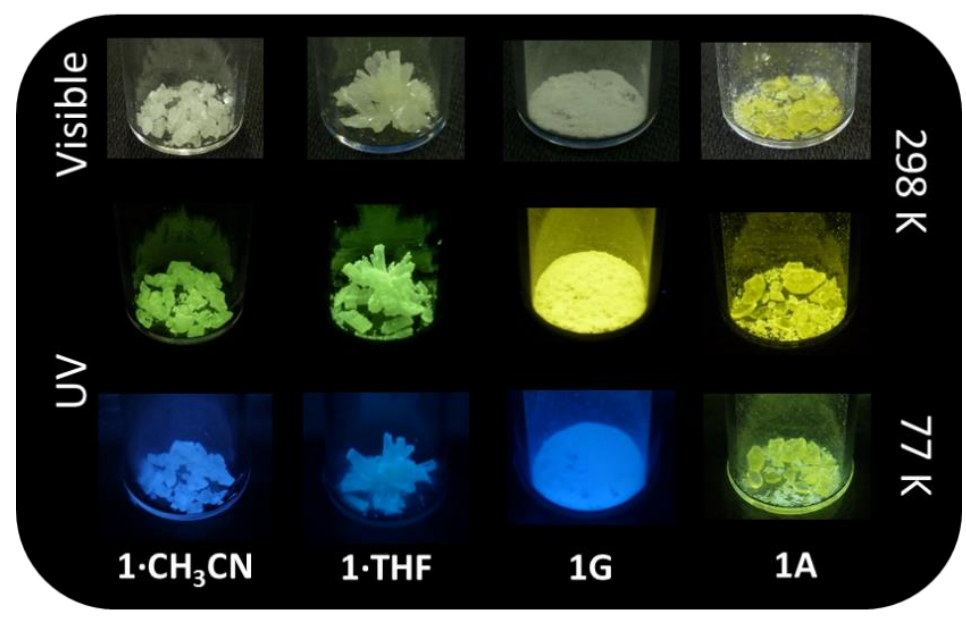

Figure 8. Photos of $\mathbf{1} \cdot \mathbf{C H}_{3} \mathbf{C N}, \mathbf{1} \cdot \mathbf{T H F}, \mathbf{1 G}$ and $\mathbf{1 A}$ under visible light and UV excitation $(365 \mathrm{~nm})$, at room temperature and at $77 \mathrm{~K}$.

Solid-state emission and excitation spectra were recorded from room temperature to $77 \mathrm{~K}$ and are reported in Figure 9 (whole temperature range in Figure S13), and the selected data are summarized in Table 2. At $293 \mathrm{~K}$ (Figure 9), 1 $\mathbf{\bullet T H F}$ and $\mathbf{1} \cdot \mathbf{C} \mathbf{H}_{\mathbf{3}} \mathbf{C N}$ display a single broad emission band (labelled LE for low energy) centered at $\lambda_{\max }=540$ and $542 \mathrm{~nm}\left(\lambda_{\mathrm{ex}}=350 \mathrm{~nm}\right)$, respectively. After grinding (1G), this band is shifted to $\lambda_{\max }=560 \mathrm{~nm}$. This bathochromic shift of $20 \mathrm{~nm}$ can be easily detected by the naked eyes because of eyes sensitivity in the yellow-green spectral region. The emission band of $\mathbf{1 A}$ is centered at $577 \mathrm{~nm}$, in accordance with its yellow emission. Therefore, the emission band of 1G just lies between that of the pristine crystalline phase and that of 1A. The corresponding absolute internal quantum yields measured at room temperature present high values of 73,55 and $43 \%$ for $\mathbf{1} \cdot \mathbf{C H}_{3} \mathbf{C N}$, $\mathbf{1}$ THF and $\mathbf{1 G}$ respectively, and a lower one of $10 \%$ for $\mathbf{1 A}$. The higher absorption of $\mathbf{1 A}$ in the visible region can explain this lower value. Emission lifetimes were recorded at room temperature (Figure S14) and $\mathbf{1} \cdot \mathbf{T H F}$ and $\mathbf{1} \cdot \mathbf{C H}_{3} \mathbf{C N}$ present a single exponential decay of $\tau=3.67$ and $3.91 \mu$ s, respectively. In contrast, data of $\mathbf{1 G}$ and $\mathbf{1 A}$ are best fitted as biexponential decays with $\tau_{1}=1.19$ and $\tau_{2}=4.33 \mu \mathrm{s}$ and $\tau_{1}$ $=1.41 \mu \mathrm{s}$ and $\tau_{2}=4.86 \mu \mathrm{s}$, respectively. For $\mathbf{1 G}$, this behavior can be explained by its dual composition; with the amorphous part having a shorter lifetime compared with that of the pristine crystalline phase. The behavior of $\mathbf{1 A}$ can be explained by its disordered state with different emissive centers.
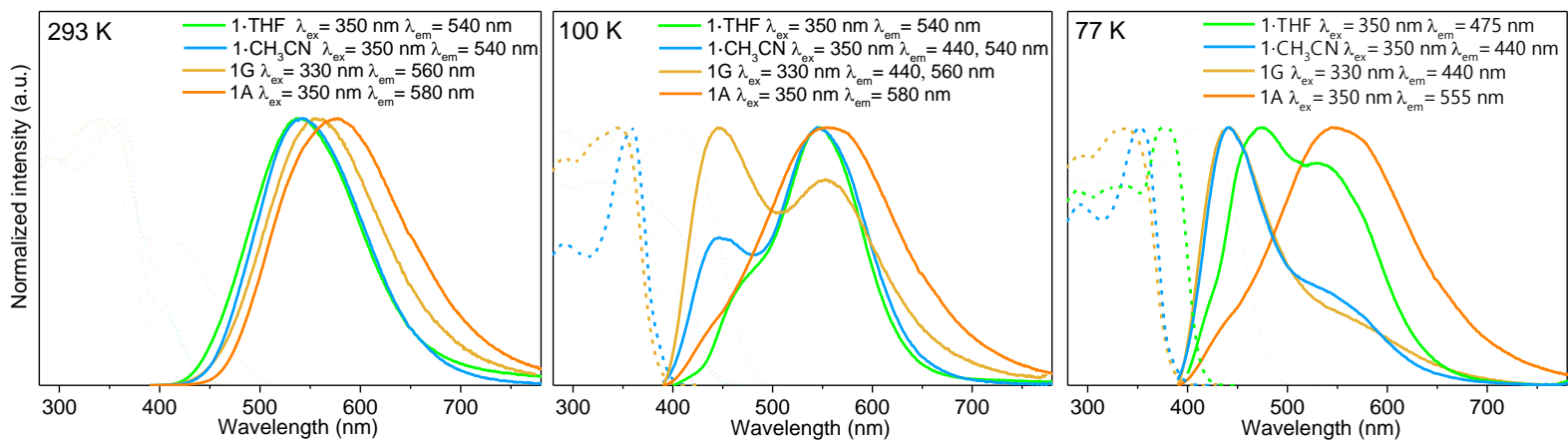

Figure 9. Emission (solid lines) and excitation (dotted lines for LE and dashed lines for HE band) normalized spectra of $\mathbf{1} \cdot \mathbf{C H}_{3} \mathbf{C N}, \mathbf{1} \cdot \mathbf{T H F}, \mathbf{1 G}$ and $\mathbf{1 A}$ at 293,100 and $77 \mathrm{~K}$. 
The luminescence thermochromism observed for $1 \mathbf{}^{\bullet} \mathbf{C H}_{3} \mathbf{C N}, \mathbf{1} \mathbf{T H F}$ and $\mathbf{1 G}$ is characterized by the appearance, by lowering the temperature, of a new emission band at higher energy (labelled HE for high energy). At $77 \mathrm{~K}$, the $\mathrm{HE}$ band is centered at 442,474 and $442 \mathrm{~nm}$ for $\mathbf{1} \cdot \mathbf{C H}_{3} \mathbf{C N}, \mathbf{1} \cdot \mathbf{T H F}$ and $\mathbf{1 G}$, respectively (Figure 9). At this temperature, the LE band is still present at $535 \mathrm{~nm}$ for $\mathbf{1} \mathbf{T H F}$ that is different for $\mathbf{1} \cdot \mathbf{C H}_{3} \mathbf{C N}$ and $\mathbf{1 G}$ for which it is almost extinguished. These results are in agreement with the turquoise and blue emission displayed by these compounds. For $\mathbf{1 A}$, only a weak HE band (shoulder) around $430 \mathrm{~nm}$ is observed at $77 \mathrm{~K}$. Upon lowering the temperature, the temperature-dependent spectra of the four compounds show first an increase of the intensity of the LE band followed by a decrease (Figure S13). The increase is relative to classical enhancement of radiative processes and the decrease is concomitant with the progressive increase in intensity of the HE band. Limited shifts of the emission wavelengths are observed with the temperature for $\mathbf{1}^{\cdot} \mathbf{C H}_{3} \mathbf{C N}, \mathbf{1} \cdot \mathbf{T H F}$, and $\mathbf{1 G}$. In the case of $\mathbf{1 A}$, a blue shift of $26 \mathrm{~nm}$ of the LE band is observed from 293 to $77 \mathrm{~K}$, which is in accordance with the yellow to green emission color change. Excitation spectra present broad features with main contribution around $350 \mathrm{~nm}$ and expanded beyond $400 \mathrm{~nm}$. In the low-energy region, 1A presents more intense excitation band in accordance with its slight yellow color.

Table 2. Photoluminescence data of the studied compounds at different temperature. Lifetimes $(\tau)$ and quantum yields (QY) were recorded at $293 \mathrm{~K}$.

\begin{tabular}{|c|c|c|c|c|c|c|c|}
\hline & \multirow{2}{*}{$\begin{array}{c}\lambda_{\lambda_{\mathrm{em}}^{\max }\left[\lambda_{\mathrm{ex}}\right]} \\
(\mathrm{nm}) \\
293 \mathrm{~K} \\
\mathbf{L E}\end{array}$} & \multicolumn{2}{|c|}{$\begin{array}{c}\lambda^{\lambda_{\text {em }}^{\max }\left[\lambda_{\text {ex }}\right]} \\
(\mathbf{n m}) \\
100 \mathrm{~K}\end{array}$} & \multicolumn{2}{|c|}{$\begin{array}{c}\lambda^{\lambda_{\text {em }}^{\max }\left[\lambda_{\mathrm{ex}}\right]} \\
(\mathrm{nm}) \\
77 \mathrm{~K}\end{array}$} & \multirow[t]{2}{*}{$\begin{array}{c}\tau(\mu \mathrm{s}) \\
{\left[\lambda_{\mathrm{ex}}=266 \mathrm{~nm}\right]}\end{array}$} & \multirow[t]{2}{*}{$\begin{array}{c}\text { QY (\%) } \\
{\left[\lambda_{\text {ex }}=350 \mathrm{~nm}\right]}\end{array}$} \\
\hline & & HE & LE & HE & LE & & \\
\hline $1 \cdot \mathrm{CH}_{3} \mathrm{CN}$ & $\begin{array}{c}542 \\
{[350]}\end{array}$ & $\begin{array}{c}448 \\
{[350]}\end{array}$ & $\begin{array}{c}547 \\
{[350]}\end{array}$ & $\begin{array}{c}442 \\
{[350]}\end{array}$ & 542 & 3.91 & 73 \\
\hline 1•THF & $\begin{array}{c}540 \\
{[350]}\end{array}$ & - & $\begin{array}{c}547 \\
{[350]}\end{array}$ & $\begin{array}{c}474 \\
{[350]}\end{array}$ & $\begin{array}{c}535 \\
{[350]}\end{array}$ & 3.67 & 55 \\
\hline $1 G$ & $\begin{array}{c}560 \\
{[330]}\end{array}$ & $\begin{array}{c}448 \\
{[330]}\end{array}$ & $\begin{array}{c}555 \\
{[330]}\end{array}$ & $\begin{array}{c}442 \\
{[330]}\end{array}$ & - & $\begin{array}{l}1.19 \\
4.33\end{array}$ & 43 \\
\hline $\mathbf{1 A}$ & $\begin{array}{c}577 \\
{[350]}\end{array}$ & - & $\begin{array}{c}557 \\
{[350]}\end{array}$ & - & $\begin{array}{c}551 \\
{[350]}\end{array}$ & $\begin{array}{l}1.41 \\
4.86\end{array}$ & 10 \\
\hline
\end{tabular}

To rationalize the luminescence properties of $\left[\mathrm{Cu}_{4} \mathrm{I}_{4}\left(\mathrm{PPh}_{2}\left(\mathrm{C}_{6} \mathrm{H}_{4}-\mathrm{CH}_{2} \mathrm{OH}\right)_{4}\right](\mathbf{1})\right.$, structural relaxation of the ground $\left(\mathrm{S}_{0}\right)$ and of two triplet excited states $\left(\mathrm{T}_{1}\right.$ and $\left.\mathrm{T}_{2}\right)$ were performed by DFT calculations. Selected geometric parameters of each state are given in Table 3 and their related structures are depicted in Figure S15. As shown in Table 3, the computed bond lengths are in good agreement with respect to experiment although the $\mathrm{Cu}-\mathrm{Cu}$ and $\mathrm{Cu}-\mathrm{P}$ are slightly overestimated. The used basis set is a good compromise between computational costs and accuracy, although a slight overestimation of some geometrical parameter may arise. The electronic structure of $\mathbf{1}$ at the ground state was calculated and the Kohn-Sham diagram is reported in Figure 10. The HOMO-LUMO gap is of $4.36 \mathrm{eV}$ indicating a strong thermodynamic stability. 


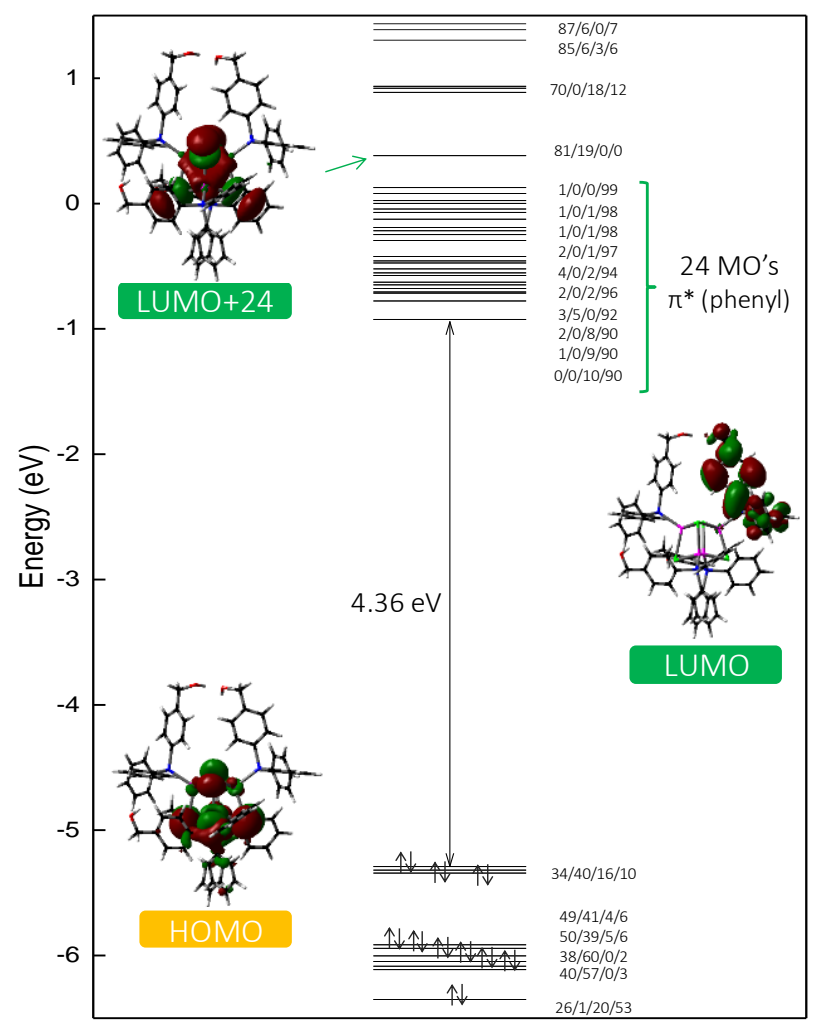

Figure 10. Kohn-Sham orbital diagram of $\left[\mathrm{Cu}_{4} \mathrm{I}_{4}\left(\mathrm{PPh}_{2}\left(\mathrm{C}_{6} \mathrm{H}_{4}-\mathrm{CH}_{2} \mathrm{OH}\right)_{4}\right]\right.$ (1) in the ground state $\left(\mathrm{S}_{0}\right)$. Orbital compositions are in the order $\mathrm{Cu} / \mathrm{I} / \mathrm{P} / \mathrm{Ph}$.

The HOMO is composed of $\mathrm{Cu} d(30 \%)$ and I $p(40 \%)$ orbitals. The first 24 lowest unoccupied orbitals are in a relatively small energy range $(0.8 \mathrm{eV})$ and are all combinations of the $\pi^{*}$ phenyl orbitals of the ligands $(\geq 90 \%)$. The LUMO +24 has a large $\mathrm{Cu} s$ contribution $(81 \%)$ with a strong metal-metal bonding character. Consequently, if one is able to put an electron into this orbital at the excited state, then the $\mathrm{Cu}-\mathrm{Cu}$ bond length is expected to be strongly shortened. The electronic transitions of lowest energy calculated by TD-DFT correspond to electron promotion from the highest occupied orbitals to the lowest unoccupied $\pi^{*}$ ones. Therefore, the transitions can be characterized as mixed halogen- and metal-toligand charge transfers, namely ${ }^{1}(\mathrm{X}, \mathrm{M}) \mathrm{LCT}$. The simulated absorption spectrum exhibits main bands in the 280-320 $\mathrm{nm}$ range that is in good agreement with the broad absorption band centered at $310 \mathrm{~nm}$ (Table 4, Figure S16). In order to interpret the observed emission properties, computations of the triplet excited states $\left(T_{1}\right.$ and $\left.T_{2}\right)$ were performed. Promoting an electron from the $\mathrm{S}_{0} \mathrm{HOMO}(\mathrm{Cu}, \mathrm{I})$ into one (or a combination) of the $\pi^{*}$ (phenyl) orbitals generates the $\mathrm{T}_{2}$ excited state. The corresponding transition is thus of ${ }^{3}(\mathrm{X}, \mathrm{M}) \mathrm{LCT}$ character. The other excited state $\mathrm{T}_{1}$, results from an electron promotion to the LUMO+24 orbital. Therefore, one may characterize the transition as a mixed ${ }^{3} \mathrm{XM}$ and intra-metal $(\mathrm{Cu}$ $d \rightarrow s$ ) charge transfers. Because this transition mainly involves the $\left[\mathrm{Cu}_{4} \mathrm{I}_{4}\right]$ cluster core, this $\mathrm{T}_{1}$ state is labelled ${ }^{3} \mathrm{CC}$ (Cluster Centered). The expected $\mathrm{Cu}-\mathrm{Cu}$ shortening between $\mathrm{S}_{0}$ and $\mathrm{T}_{1}$ is well reproduced in the simulation $(0.36 \AA,-12 \%)$ whereas a small stretching was calculated for $\mathrm{T}_{2}(0.06 \AA,+2 \%)$. Cu$\mathrm{P}$ bond lengths are almost unaffected for both triplets. However, the $\mathrm{Cu}-\mathrm{I}$ distance in $\mathrm{T}_{1}$ increases significantly with respect to the ground state $(0.19 \AA,+7 \%)$ in comparison with little change in $\mathrm{T}_{2}(0.01$ $\AA,-0.3 \%)$. The data clearly indicate that the geometry of $T_{2}$ is closer to that of $S_{0}$ compared with that of $\mathrm{T}_{1}$ (Table 3). 
Table 3. Geometrical parameters (mean values) of the optimized DFT structures at the $\mathrm{S}_{0}, \mathrm{~T}_{1}$ and $\mathrm{T}_{2}$ states along with the X-ray structural data reported in square brackets for $\mathbf{1}$.

\begin{tabular}{|l|c|c|c|}
\hline \multirow{2}{*}{} & \multicolumn{3}{|c|}{$\left[\mathbf{C u}_{\mathbf{4}} \mathbf{I}_{\mathbf{4}}\left(\mathbf{P P h}_{\mathbf{2}}\left(\mathbf{C}_{\mathbf{6}} \mathbf{H}_{\mathbf{4}}-\mathbf{C H}_{\mathbf{2}} \mathbf{O H}\right)_{4}\right]\right.$} \\
\cline { 2 - 4 } & $\mathbf{S}_{\mathbf{0}}$ & $\mathbf{T}_{\mathbf{1}}$ & $\mathbf{T}_{\mathbf{2}}$ \\
\hline HOMO-LUMO gap $(\mathrm{eV})$ & 4.36 & - & - \\
\hline Cu-Cu $(\AA)$ & $\begin{array}{c}2.998 \\
{[2.899]}\end{array}$ & 2.643 & 3.054 \\
\hline Cu-I $(\AA)$ & $\begin{array}{c}2.721 \\
{[2.687]}\end{array}$ & 2.914 & 2.712 \\
\hline Cu-P $(\AA)$ & $\begin{array}{c}2.347 \\
{[2.255]}\end{array}$ & 2.365 & 2.346 \\
\hline
\end{tabular}


Table 4. Experimental and computed absorption and luminescence data for 1. Values in parenthesis are the oscillator strengths $\left(f^{*} \geq 0.03\right)$ associated with the absorption wavelengths $\lambda(\mathrm{nm})$. Main contributions to these transitions are indicated with their corresponding weights in \%. Energies are given in square brackets.

\begin{tabular}{|c|c|c|}
\hline \multicolumn{3}{|r|}{$\left[\mathrm{Cu}_{4} \mathrm{I}_{4}\left(\mathrm{PPh}_{2}\left(\mathrm{C}_{6} \mathrm{H}_{4}-\mathrm{CH}_{2} \mathrm{OH}\right)_{4}\right]\right.$} \\
\hline & $\begin{array}{l}\text { Experimental } \\
\lambda[\mathrm{E}]\end{array}$ & $\begin{array}{c}\text { Computed } \\
\lambda\left(\mathrm{f}^{*}\right) \text { transition, } \lambda[\mathrm{E}]\end{array}$ \\
\hline $\begin{array}{l}\text { Absorption } \\
\lambda(\mathrm{nm})\end{array}$ & $\begin{array}{l}\mathbf{3 1 0}[4 \mathrm{eV}] \\
\quad(\text { broad) }\end{array}$ & $\begin{array}{l}\mathbf{2 8 3}(0.04) C u / I \rightarrow \pi * \text { phenyl } \\
\text { HOMO-2 } \rightarrow \text { LUMO+13 }(13 \%), \text { HOMO-2 } \rightarrow \text { LUMO+14 }(18 \%), \\
\text { HOMO-1 } \rightarrow \text { LUMO+14 }(18 \%) \\
\mathbf{2 8 7}(0.03) \text { Cu/I } \rightarrow \pi * \text { phenyl } \\
\text { HOMO-2 } \rightarrow \text { LUMO+10 }(27 \%), \text { HOMO } \rightarrow \text { LUMO+11 }(16 \%), \\
\text { HOMO } \rightarrow \text { LUMO+13 }(16 \%) \\
\mathbf{2 8 8}(0.04) \text { Cu/I } \rightarrow \pi * \text { phenyl } \\
\text { HOMO-2 } \rightarrow \text { LUMO+11 }(17 \%), \text { HOMO-1 } \rightarrow \text { LUMO+11 }(13 \%), \\
\text { HOMO-1 } \rightarrow \text { LUMO+13 }(14 \%), \text { HOMO } \rightarrow \text { LUMO+11 }(12 \%), \\
\text { HOMO } \rightarrow \text { LUMO+13 }(17 \%) \\
\mathbf{3 0 8}(0.04) \text { Cu/I } \rightarrow \pi * \text { phenyl } \\
\text { HOMO-2 } \rightarrow \text { LUMO+7 }(53 \%), \text { HOMO-1 } \rightarrow \text { LUMO+7 }(18 \%) \\
\mathbf{3 1 2}(0.03) \text { Cu/I } \rightarrow \pi * \text { phenyl } \\
\text { HOMO-2 } \rightarrow \text { LUMO+6 }(16 \%), \text { HOMO-1 } \rightarrow \text { LUMO+1 }(14 \%), \\
\text { HOMO-1 } \rightarrow \text { LUMO+6 }(15 \%), \text { HOMO-1 } \rightarrow \text { LUMO+8 }(11 \%) \\
\mathbf{3 1 6}(0.04) \text { Cu/I } \rightarrow \pi * \text { phenyl } \\
\text { HOMO-1 } \rightarrow \text { LUMO+5 }(24 \%), \text { HOMO } \rightarrow \text { LUMO+6 }(37 \%), \\
\text { HOMO } \rightarrow \text { LUMO+8 }(17 \%) \\
\mathbf{3 1 9 ~}(0.03) \text { Cu/I } \rightarrow \pi * \text { phenyl } \\
\text { HOMO-2 } \rightarrow \text { LUMO+2 }(15 \%), \text { HOMO-2 } \rightarrow \text { LUMO+4 }(21 \%), \\
\text { HOMO-1 } \rightarrow \text { LUMO+2 }(11 \%), \text { HOMO-1 } \rightarrow \text { LUMO+4 }(33 \%)\end{array}$ \\
\hline \multirow{2}{*}{$\begin{array}{l}\text { Emission } \\
\lambda(\mathrm{nm})\end{array}$} & $474[2.61 \mathrm{eV}] 77 \mathrm{~K}$ & $460[2.69 \mathrm{eV}] \mathrm{T}_{2} \rightarrow \mathrm{S}_{0}$ \\
\hline & $\mathbf{5 4 0}[2.30 \mathrm{eV}] 293 \mathrm{~K}$ & $555[2.23 \mathrm{eV}] \mathrm{T}_{1} \rightarrow \mathrm{S}_{0}$ \\
\hline
\end{tabular}

Regarding the simulation of the luminescence spectra, the electronic vertical emission wavelengths were computed around 460 and $555 \mathrm{~nm}$ for deexcitations from $\mathrm{T}_{2}$ and $\mathrm{T}_{1}$, respectively. These data are in very good agreement with respect to the experimental ones (474 nm (HE) and $540 \mathrm{~nm}$ (LE) in Table 4). Based on the DFT calculations, the luminescence thermochromism observed for the studied compounds can be explained as following. At $77 \mathrm{~K}$, the $\mathrm{T}_{2}$ state of lowest energy is populated and is responsible for the HE emission. When the temperature increases, $T_{1}$ starts to be populated and $T_{2}$ depopulated leading to the LE emission. The thermal equilibrium between these two excited states is at the origin of the intensity variation of the $\mathrm{HE}$ and LE emission bands with the temperature. This result is in agreement with previous studies on cubane copper iodide clusters. ${ }^{59,60}$ To simulate the whole luminescence properties of $\mathbf{1}$, the spectral shape of both HE and LE emission spectra were simulated independently (Figure 11a). The experimental emission band at $293 \mathrm{~K}$ (LE) is in very good agreement with the simulated curve obtained for the $\mathrm{T}_{1}$ state. The two emission bands (HE and LE) observed at $77 \mathrm{~K}$ are also well reproduced by combination of the spectra individually calculated for the $T_{1}$ and $T_{2}$ states. Reports on the chromaticity diagram illustrates the good accordance between the experimental and theoretical data (Figure 11b). The thermochromism can be thus completely interpreted and its two excited states origin is confirmed. The calculations allow the reproduction of the phosphorescence spectra and the thermochromic behavior that is unprecedented for $\left[\mathrm{Cu}_{4} \mathrm{I}_{4} \mathrm{~L}_{4}\right]$ clusters and were rarely performed on high nuclearity systems. ${ }^{61}$ 

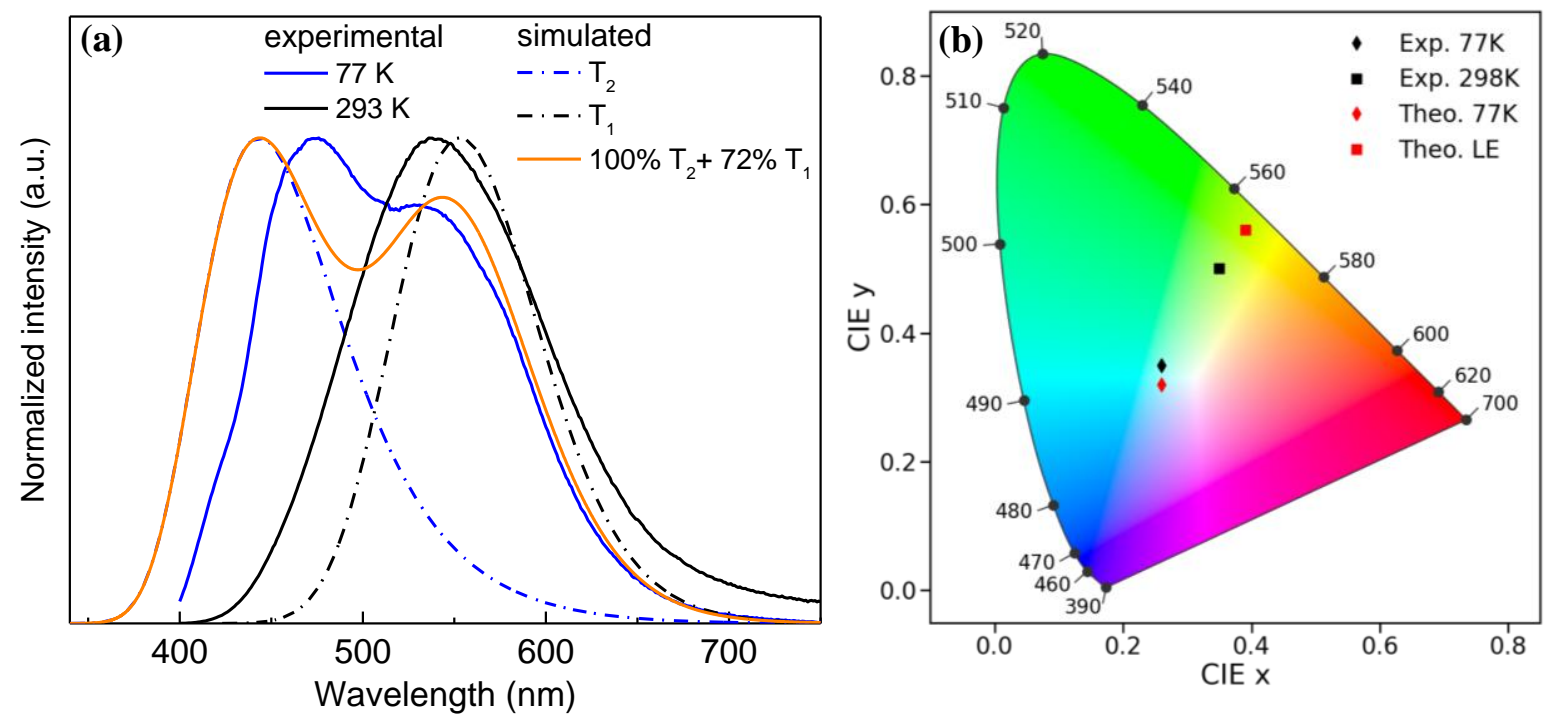

Figure 11. (a) Simulated emission spectra of $T_{1}$ and $T_{2}$ triplet states and experimental spectra of 1•THF at 293 and $77 \mathrm{~K}$. A suggested combination of the two simulated spectra (orange curve) fits the low temperature experimental emission spectra at 77 K. (b) CIE 1931 chromaticity diagram with experimental and calculated data.

\section{Conclusions}

The luminescence mechanochromism of $\left[\mathrm{Cu}_{4} \mathrm{I}_{4}\left(\mathrm{PPh}_{2}\left(\mathrm{C}_{6} \mathrm{H}_{4}-\mathrm{CH}_{2} \mathrm{OH}\right)\right)_{4}\right]$ (1) is characterized by a contrasted emission color change from green to yellow. From PXRD, this emission shift is accompanied by a crystalline-to-amorphous transition. This transition is only partial and as quantified by solid-state NMR analysis, $75 \%$ of the pristine crystalline phase remains intact after the mechanical solicitation. The solid-state NMR analysis also demonstrated that the amorphous phase created upon grinding $(25 \%$ of 1G) presents similarities with the totally amorphous phase $\mathbf{1 A}$, obtained by melting the crystalline phase. From ${ }^{31} \mathrm{P}$ solid-state NMR and IR analysis, the cluster core has been modified by the applied mechanical forces with modifications of the $\mathrm{Cu}-\mathrm{Cu}, \mathrm{Cu}-\mathrm{I}$ and $\mathrm{Cu}-\mathrm{P}$ bonds. The IR spectra of $\mathbf{1 G}$ is similar to $\mathbf{1 A}$ and both of them present similarities with that of $\mathbf{1} \cdot \mathbf{C H}_{3} \mathbf{C N}$. This suggests that the $\left[\mathrm{Cu}_{4} \mathrm{I}_{4}\right]$ cluster core in the amorphous phases has a more symmetrical geometry as that observed in the SCXRD analysis of $\mathbf{1} \cdot \mathbf{C H}_{3} \mathbf{C N}$ compared with the more distorted one in $\mathbf{1} \cdot \mathbf{T H F}$.

In accordance with the amorphous composition of $\mathbf{1 G}$, its luminescence properties are characterized at room temperature by an emission band (LE) lying between that of the crystalline and the melted phases. This is also in agreement with the two different lifetimes values, also measured for $\mathbf{1 A}$ indicating a disordered phase within are clusters of different emissive molecular structures. DFT calculations assigned the LE emission band to a CC transition (XMCT, MM) and demonstrated that the corresponding excited state is of $\mathrm{Cu}-\mathrm{Cu}$ bonding character with a shortening of the $\mathrm{Cu}-\mathrm{Cu}$ distances. Therefore, with a redshift of the emission, a shortening of the $\mathrm{Cu}-\mathrm{Cu}$ must occurs in the amorphous phases. In these disordered phases, the cluster presents less structural constraints compared with the crystalline state, leading to a relaxed geometry with shorter $\mathrm{Cu}-\mathrm{Cu}$ interactions. The larger redshift is actually observed for the complete amorphous phase 1A. The SCXRD molecular structures of the clusters in $\mathbf{1} \cdot \mathbf{C H}_{3} \mathbf{C N}$ and $\mathbf{1}$ THF present differences as detected by IR and NMR analysis, while their emission wavelengths are nearly similar. This means that these differences are not large enough to impact the emission and that structural changes occurring in $\mathbf{1 G}$ and $\mathbf{1 A}$ are consequently more important. 
The luminescence thermochromism displayed by the studied compounds is characterized by the variation in temperature of the relative intensity of two emission bands, LE and HE. While the LE band is predominant at room temperature, the HE one appears progressively when the temperature is lowered. Its origin also contrasts with that of the LE band and implies in this case the ligand with a (X,M)LCT character. This thermochromism being typical of cubane copper iodide clusters, the preservation of the cubane structure is therefore attested in 1G. The different thermochromism behavior between $\mathbf{1 G}$ and 1.THF constitutes another demonstration of the modification of the molecular structure of the cluster upon grinding. Great similarities with the emission properties of $\mathbf{1} \cdot \mathbf{C H}_{\mathbf{3}} \mathbf{C N}$ is an additional confirmation. For $\mathbf{1 A}$, the HE band is hardly distinguished and must appears at lower temperature. In this case, the thermal transfer between the two excited states must be more efficient and a lower temperature is needed to trap the emission at the $(\mathrm{X}, \mathrm{M}) \mathrm{LCT}$ emissive state. The less efficient transfer in 1G, indicates that the $\mathrm{Cu}-\mathrm{Cu}$ interactions are not the only parameter to consider in the thermal transfer between the two excited states.

The mechanochromism mechanism can be ascribed to a collapse of the intermolecular interactions upon the effect of mechanical forces. This is in accordance with the modification of the hydrogen bond networks shown in the IR analysis. This crystalline packing alteration induces modifications of the molecular structure of the cluster and in particular towards a cluster core of more symmetric geometry and with shorter $\mathrm{Cu}-\mathrm{Cu}$ distances leading, as explained before, to the modification of the emissive properties.

To conclude, these results demonstrate that the combined study of crystalline polymorphism and amorphous state is gainful to the understanding of the mechanochromism phenomenon. Characterizations of the amorphous phase being the ultimate state of the grinding altered state, give insight into the mechanochromism mechanism. In accordance to previous reports, the intermolecular cuprophilic interactions are involved in the mechanochromism mechanism but this study shows that the geometry of the cluster core in whole, has to be considered. Getting deeper into the understanding of the mechanochromism mechanism is beneficial for the development of mechanically-sensitive materials. By combining multi-stimuli responsive properties, copper iodide clusters constitute an appealing class of compounds with applicative perspectives towards original functional materials. Furthermore, the possibility to obtain amorphous phase of such compounds represent relevant processing facilities for the development of the fore-mentioned materials.

\section{Acknowledgments.}

R. U.-M. thanks the DGA and the 'Région Pays de la Loire' for her Ph.D. fellowship. C.M.C. is grateful for financial support from the Institut Universitaire de France (IUF). Financial support from the IRRMN-THC Fr3050 CNRS for conducting the research is gratefully acknowledged. CCIPL (Centre de Calculs Intensifs des Pays de Loire) is acknowledged for computational resources.

\section{ASSOCIATED CONTENT.}

Supporting Information Available. The X-ray crystallographic files (CIF), the experimental section, the DFT and other characterization data. This information is available free of charge via the Internet at http://pubs.acs.org. 


\section{References}

(1) Huang, G.; Xia, Q.; Huang, W.; Tian, J.; He, Z.; Li, B. S.; Tang, B. Z. Multiple Anti-Counterfeiting Guarantees from a Simple Tetraphenylethylene Derivative - High-Contrasted and Multi-State Mechanochromism and Photochromism. Angew. Chem. Int. Ed. 2019, 58, 17814-17819.

(2) Naren, G.; Hsu, C.-W.; Li, S.; Morimoto, M.; Tang, S.; Hernando, J.; Guirado, G.; Irie, M.; Raymo, F. M.; Sundén, H.; Andréasson, J.; An all-photonic full color RGB system based on molecular photoswitches. Nature Com. 2019, 3996-4003.

(3) Jiang, T.; Zhu, Y.-F.; Zhang, J.-C.; Zhu, J.; Zhang, M.; Qiu, J. Multistimuli-Responsive Display Materials to Encrypt Differentiated Information in Bright and Dark Fields. Adv. Funct. Mater. 2019, 29, 1906068.

(4) Li, W.; Huang, Q.; Mao, Z.; Zhao, J.; Wu, H.; Chen, J.; Yang, Z.; Li, Y.; Yang, Z.; Zhang, Y.; Aldred, M. P.; Chi, Z. Selective Expression of Chromophores in a Single Molecule: Soft Organic Crystals Exhibiting Full-Colour Tunability and Dynamic Triplet-Exciton Behaviours. Angew. Chem. Int. Ed. 2020, 59, 3739-3745.

(5) Kato, M.; Ito, H.; Hasegawa, M.; Ishii, K. Soft Crystals: Flexible Response Systems with High Structural Order. Chem. Eur. J. 2019, 25, 5105-5112.

(6) Yao, Z.-Q.; Xu, J.; Zou, B.; Hu, Z.; Wang, K.; Yuan, Y.-J.; Chen, Y.-P.; Feng, R.; Xiong, J.-B.; Hao, J.; Bu, X.-H. A Dual-Stimuli-Responsive Coordination Network Featuring Reversible Wide-Range LuminescenceTuning Behavior. Angew. Chem. Int. Ed. 2019, 58, 5614-5618.

(7) Wang, C.; Wang, D.; Kozhevnikov, V.; Dai, X.; Turnbull, G.; Chen, X.; Kong, J.; Tang, B. Z.; Li, Y.; Xu, B. B. A flexible topo-optical sensing technology with ultra-high contrast. Nat. Commun. 2020, 11, 1447-1453.

(8) Sagara, Y.; Kato, T. Mechanically induced luminescence changes in molecular assemblies. Nat. Chem. 2009, 1, 605-610.

(9) Balch, A. L. Dynamic Crystals: Visually Detected Mechanochemical Changes in the Luminescence of Gold and Other Transition-Metal Complexes. Angew. Chem. Int. Ed. 2009, 48, 2641-2644.

(10) Ariga, K.; Mori, T.; Hill, J. P. Mechanical Control of Nanomaterials and Nanosystems. Adv. Mater. 2012, 24, 158-176.

(11) Ciardelli, F.; Ruggeri, G.; Pucci, A. Dye-containing polymers: methods for preparation of mechanochromic materials. Chem. Soc. Rev. 2013, 42, 857-870.

(12) Qiu, Z.; Zhao, W.; Cao, M.; Wang, Y.; Lam, J. W. Y.; Zhang, Z.; Chen, X.; Zhong Tang, B. Dynamic Visualization of Stress/Strain Distribution and Fatigue Crack Propagation by an Organic Mechanoresponsive AIE Luminogen. Adv. Mater. 2018, 30, 1803924.

(13) Wintzheimer, S.; Reichstein, J.; Wenderoth, S.; Hasselmann, S.; Oppmann, M.; Seuffert, M. T.; MüllerBuschbaum, K.; Mandel, K. Expanding the Horizon of Mechanochromic Detection by Luminescent Shear Stress Sensor Supraparticles. Adv. Funct. Mater. 2019, 29, 1901193.

(14) Xue, P.; Ding, J.; Wang, P.; Lu, R. Recent progress in the mechanochromism of phosphorescent organic molecules and metal complexes. J. Mater. Chem. C, 2016, 4, 6688-6706.

(15) Roberts, D. R. T.; Holder, S. J. Mechanochromic systems for the detection of stress, strain and deformation in polymeric materials. J. Mater. Chem. 2011, 21, 8256-8268.

(16) Dal Molin, M.; Verolet, Q.; Soleimanpour, S.; Matile, S. Mechanosensitive Membrane Probes. Chem. Eur. J. 2015, 21, 6012-6021.

(17) Sun, H.; Liu, S.; Lin, W.; Zhang, K. Y.; Lv, W.; Huang, X.; Huo, F.; Yang, H.; Jenkins, G.; Zhao, Q.; Huang, W. Smart responsive phosphorescent materials for data recording and security protection. Nat. Commun. 2014, 5, 3601-3609.

(18) Lu, S.; Xiao, G.; Sui, L.; Feng, T.; Yong, X.; Zhu, S.; Li, B.; Liu, Z.; Zou, B.; Jin, M.; Tse, J. S.; Yan, H.; Yang, B. Piezochromic Carbon Dots with Two-photon Fluorescence. Angew. Chem. Int. Ed. 2017, 56, 6187-6191.

(19) Sagara, Y.; Karman, M.; Verde-Sesto, E.; Matsuo, K.; Kim, Y.; Tamaoki, N.; Weder. C.; Rotaxanes as Mechanochromic Fluorescent Force Transducers in Polymers. J. Am. Chem. Soc. 2018, 140, 1584-1587.

(20) Calvino, C.; Guha, A.; Weder, C.; Schrettl S. Self-Calibrating Mechanochromic Fluorescent Polymers Based on Encapsulated Excimer-Forming Dyes. Adv. Mater. 2018, 30, 1704603.

(21) (a) Chi, Z.; Zhang, X.; Xu, B.; Zhou, X.; Ma, C.; Zhang, Y.; Liu, S.; Xu, J. Recent advances in organic mechanofluorochromic materials. Chem. Soc. Rev. 2012, 41, 3878-3896. (b) Ma, Z.; Wang, Z.; Meng, X.; Ma, Z.; 
Xu, Z.; Ma, Y.; Jia, X. A Mechanochromic Single Crystal: Turning Two Color Changes into a Tricolored Switch. Angew. Chem., Int. Ed. 2016, 55, 519-522.

(22) Zhang, X.; Chi, Z.; Zhang, Y.; Liu, S.; Xu, J. Recent advances in mechanochromic luminescent metal complexes. J. Mater. Chem. C, 2013, 1, 3376-3390.

(23) Tsujimoto, H.; Ha, D.-G.; Markopoulos, G.; Chae, H. S.; Baldo, M. A.; Swager, T. M. Thermally Activated Delayed Fluorescence and Aggregation Induced Emission with Through-Space Charge Transfer. J. Am. Chem. Soc. 2017, 139, 4894-4900.

(24) Yang, Z.; Chi, Z.; Mao, Z.; Zhang, Y.; Liu, S.; Zhao, J.; Aldred, M. P.; Chi, Z. Recent advances in mechanoresponsive luminescence of tetraphenylethylene derivatives with aggregation-induced emission properties. Mater. Chem. Front., 2018, 2, 861-890.

(25) See for examples: (a) Schneider, J.; Lee, Y.-A.; Pérez, J.; Brennessel, W. W.; Flaschenriem, C.; Eisenberg, R. Strong Intra- and Intermolecular Aurophilic Interactions in a New Series of Brilliantly Luminescent Dinuclear Cationic and Neutral Au(I) Benzimidazolethiolate Complexes. Inorg. Chem. 2008, 47, 957-968. (b) Catalano, V. J.; Horner, S. J. Luminescent Gold(I) and Silver(I) Complexes of 2-(Diphenylphosphino)- 1-methylimidazole (dpim): Characterization of a Three-Coordinate $\mathrm{Au}(\mathrm{I})-\mathrm{Ag}(\mathrm{I})$ Dimer with a Short Metal-Metal Separation. Inorg. Chem. 2003, 42, 8430-8438. (c) Assefa, Z. A.; Omary, M.;

McBurnett, B. G.; Mohamed, A. A.; Patterson, H. H.; Staples, R. J.; Fackler, J. P. Syntheses, Structure, and Photoluminescence Properties of the 1-Dimensional Chain Compounds [(TPA)2Au] $[\mathrm{Au}(\mathrm{CN}) 2]$ and (TPA)AuCl (TPA = 1,3,5-Triaza-7-phosphaadamantane. Inorg. Chem. 2002, 41, 6274-6280. (d) Laguna, A.; Lasanta, T.; Lopez-de-Luzuriaga, J. M.; Monge, M.; Naumov, P.; Olmos, M. E. Combining Aurophilic Interactions and Halogen Bonding To Control the Luminescence from Bimetallic Gold-Silver Clusters. J. Am. Chem. Soc. 2010, 132, 456-457. (e) Osawa, M.; Kawata, I.; Igawa, S.; Hoshino, M.; Fukunaga, T.; Hashizume, D. Vapochromic and Mechanochromic Tetrahedral Gold(I) Complexes Based on the 1,2-Bis-(diphenylphosphino)benzene Ligand. Chem. Eur. J. 2010, 16, 12114-12126. (f) Koshevoy, I. O.; Lin, C.-L.; Karttunen, A. J.; Haukka, M.; Shih, C.-W.; Chou, P.-T.; Tunik, S. P.; Pakkanen, T. A. Octanuclear gold(I) alkynyl-diphosphine clusters showing thermochromic luminescence. Chem. Commun. 2011, 47, 5533-5535. (g) Deak, A.; Jobbagy, C.; Marsi, G.; Molnar, M.; Szakacs, Z; Baranyai, P. Anion-, Solvent-, Temperature-, and Mechano-Responsive Photoluminescence in Gold(I) Diphosphine-Based Dimers. Chem. Eur. J. 2015, 21, 11495-11508. (h) Chen, Z.; Liang, J.; Nie, Y.; Xu, X.; Yu, G.-A.; Yin, J.; Liu, S. H. A novel carbazole-based gold(I) complex with interesting solid-state, multistimuli-responsive characteristics. Dalton Trans. 2015, 44, 17473-17477. (i) Seki, T.; Kobayashi, K.; Mashimo, T.; Ito H. A gold isocyanide complex with a pendant carboxy group: orthogonal molecular arrangements and hypsochromically shifted luminescent mechanochromism Chem. Commun., 2018, 54, 1113611139. (j) Leung, M.-Y.; Leung, S. Y.-L.; Yim, K.-C.; Chan, A. K.-W. M.; Ng, Yam, V. W.-W. Metal-Metal and $\pi-\pi$ Interactions Directed End-to-End Assembly of Gold Nanorods. J. Am. Chem. Soc. 2019, 141, 19466-19478. (j) Walters, D. T.; Powers, X. B.; Olmstead, M. M.; Balch, A. L. The Preparation of Luminescent, Mechanochromic Molecular Containers from Non-Emissive Components: The Box Cations, $\left[\mathrm{Au}_{6}(\mathrm{Triphos})_{4} \mathrm{Br}\right]^{5+}$ and $\left[\mathrm{Au}_{6}\left(\operatorname{Triphos}_{4} \mathrm{Br}_{2}\right]^{4+}\right.$. Chem. Eur. J. 2019, 25, 3849-3857. (k) Dong, Y.; Zhang, J.; Li, A.; Gong, J.; He, B.; Xu, S.; Yin, J.; Liu, S. H.; Tang, B. Z. Structure-tuned and thermodynamically controlled mechanochromic selfrecovery of AIE-active Au(I) complexes. J. Mater. Chem. C, 2020, 8, 894-899. (l) Seki, T.; Ida, K.; Sato, H.; Aono, S.; Sakaki, S.; Ito, H. Aurophilicity-Mediated Construction of Emissive Porous Molecular Crystals as Versatile Hosts for Liquid and Solid Guests. Chem. Eur. J. 2020, 26, 735-744.

(26) See for examples: (a) Kozhevnikov, V. N.; Donnio, B.; Bruce, D. W. Phosphorescent, Terdentate, LiquidCrystalline Complexes of Platinum(II): Stimulus-Dependent Emission. Angew. Chem., Int. Ed., 2008, 47, 6286. (b) Nishiuchi, Y.; Takayama, A.; Suzuki, T.; Shinozaki, K. A Polymorphic Platinum(II) Complex: Yellow, Red, and Green Polymorphs and X-ray Crystallography of $[\mathrm{Pt}(\mathrm{fdpb}) \mathrm{Cl}]$ [Hfdpb $=1,3$-Bis $(5$-trifluoromethyl-2pyridyl)benzene]. Eur. J. Inorg. Chem. 2011, 1815-1823. (c) S Choi, S. J.; Kuwabara, J.; Nishimura, Y.; Arai, T.; Kanbara, T. Two-step Changes in Luminescence Color of Pt(II) Complex Bearing an Amide Moiety by Mechanoand Vapochromism. Chem. Lett., 2012, 41, 65-67. (d) Zhang, X.; Wang, J.-Y.; Ni, J.; Zhang, L.-Y.; Chen, Z.-N. Vapochromic and Mechanochromic Phosphorescence Materials Based on a Platinum(II) Complex with 4Trifluoromethylphenylacetylide. Inorg. Chem. 2012, 51, 5569-5579. (e) Huang, L.-M.; Tu, G.-M.; Chi, Y.; Hung, W.-Y.; Song, Y.-C.; Tseng, M.-R.; Chou, P.-T.; Lee, G.-H.; Wong, K.-T.; Cheng, S.-H.; Tsai, W.-S. Mechanoluminescent and efficient white OLEDs for Pt(II) phosphors bearing spatially encumbered pyridinyl pyrazolate chelates. Mater. Chem. C, 2013, 1, 7582-7592. (f) Han, A.; Du, P.; Sun, Z.; Wu, H.; Jia, H.; Zhang, R.; 
Liang, Z.; Cao, R.; Eisenberg, R. Reversible Mechanochromic Luminescence at Room Temperature in Cationic Platinum(II) Terpyridyl Complexes. Inorg. Chem. 2014, 53, 3338-3344. (g) Ohno, K.; Yamaguchi, S.; Nagasawa, A.; Fujihara, T. Mechanochromism in the luminescence of novel cyclometalated platinum(II) complexes with $\alpha$ aminocarboxylates. Dalton Trans. 2016, 45, 5492-5503. (h) Chowdhury, A.; Howlader, P.; Mukherjee, P. S. Mechano-fluorochromic PtII Luminogen and Its Cysteine Recognition. Chem. Eur. J. 2016, 22, 1424-1434. (i) Cuerva, C.; Campo, J. A.; Cano, M.; Lodeiro, C. Multi-Stimuli-Responsive Properties of Aggregation-Enhanced Emission-Active Unsymmetrical PtII Metallomesogens through Self-Assembly. Chem. Eur. J. 2019, 25, 1204612051. (j) Zhang, X.; Zhang, L.-Y.; Wang, J.-Y.; Dai, F.-R.; Chen, Z.-N. Two-step phosphorescent mechanochromism due to intramolecular deformation. J. Mater. Chem. C, 2020, 8, 715-720.

(27) Huang, X.; Qian, L.; Zhou, Y.; Liu, M.; Cheng, Y.; Wu, H. Effective structural modification of traditional fluorophores to obtain organic mechanofluorochromic molecules. J. Mater. Chem. C, 2018, 6, 5075-5096.

(28) Ito, H.; Muromoto, M.; Kurenuma, S.; Ishizaka, S.; Kitamura, N.; Sato, H.; Seki, T. Mechanical stimulation and solid seeding trigger single-crystal-to-single-crystal molecular domino transformations. Nat. Commun., 2013, 4, 2009-2014.

(29) Shirota, Y. Photo- and electroactive amorphous molecular materials - molecular design, syntheses, reactions, properties, and applications. J. Mater. Chem., 2005, 15, 75-93.

(30) Lv, Y.; Liu, Y.; Ye, X.; Liu, G.; Tao, X. The effect of mechano-stimuli on the amorphous-to-crystalline transition of mechanochromic luminescent materials. Cryst. Eng. Comm, 2015, 17, 526-531.

(31) (a) Butler, T.; Wang, F.; Daly, M. L.; DeRosa, C. A.; Dickie, D. A.; Sabat, M.; Fraser C. L. Supercooled Liquid $\beta$-Diketones with Mechanoresponsive Emission. J. Phys. Chem. C 2019, 123, 25788-25800. (b) Butler, T.;

Wang, F.; Sabat, M.; Fraser, C. L. Controlling solid-state optical properties of stimuli responsive dimethylaminosubstituted dibenzoylmethane materials. Mater. Chem. Front., 2017, 1, 1804-1817.

(32) Qi, Y.; Ding, N.; Wang, Z.; Xu, L.; Fang, Y. Mechanochromic Wide-Spectrum Luminescence Based on a Monoboron Complex. ACS Appl. Mater. Interfaces 2019, 11, 8676-8684.

(33) Yagai, S.; Seki, T.; Aonuma, H.; Kawaguchi, K.; Karatsu, T.; Okura, T.; Sakon, A.; Uekusa, H.; Ito, H. Mechanochromic Luminescence Based on Crystal-to-Crystal Transformation Mediated by a Transient Amorphous State. Chem. Mater. 2016, 28, 234-241.

(34) Cu-based complexes: (a) T. Wen, D.-X. Zhang, J. Liu, R. Lin, J. Zhang, A multifunctional helical $\mathrm{Cu}(\mathrm{I})$ coordination polymer with mechanochromic, sensing and photocatalytic properties. Chem. Commun. 2013, 49, 5660-5662. (b) T. Wen, D.-X. Zhang, H.-X. Zhang, H.-B. Zhang, J Zhang, D.-S. Li, Redox-active Cu(I) boron imidazolate framework for mechanochromic and catalytic applications. Chem. Commun. 2014, 50, 8754-8756. (c) T. Wen, X.-P. Zhou, D.-X. Zhang, D. Li, Luminescent Mechanochromic Porous Coordination Polymers. Chem. Eur. J. 2014, 20, 644-648. (d) Q. Xiao, J. Zheng, M. Li, S.-Z. Zhan, J.-H. Wang, D. Li Boomishankar, Mechanically Triggered Fluorescence/Phosphorescence Switching in the Excimers of Planar Trinuclear Copper(I) Pyrazolate Complexes. Inorg. Chem. 2014, 53, 11604-11615. (e) M. S. Deshmukh, A. Yadav, R. Pant, R. Boomishankar, Thermochromic and Mechanochromic Luminescence Umpolung in Isostructural Metal-Organic Frameworks Based on $\mathrm{Cu}_{6} \mathrm{I}_{6}$ Clusters. Inorg. Chem. 2015, 54, 1337-1345. (f) K. Chen, M. M. Nenzel, T. M. Brown,

V. J. Catalano, Luminescent Mechanochromism in a Gold(I)-Copper(I) N-Heterocyclic Carbene Complex. Inorg.

Chem. 2015, 54, 6900-6909. (g) E. Kwon, J. Kim, K. Y. Lee, T. H. Kim, Non-Phase-Transition Luminescence Mechanochromism of a Copper(I) Coordination Polymer. Inorg. Chem. 2017, 56, 943-949. (h) L.-X. Hu, M. Gao, T. Wen, Y. Kang, S. Chen, Synthesis of Halide-Modulated Cuprous(I) Coordination Polymers with Mechanochromic and Photocatalytic Properties. Inorg. Chem. 2017, 56, 6507-6511. (i) D.-X. Zhang, H.-X. Zhang, T. Wen, D.-S. Lia, J. Zhang, Mechanochromic $\mathrm{Cu}(\mathrm{I})$ boron imidazolate frameworks with low-dimensional structures and reducing function. Inorg. Chem. Front. 2016, 3, 263-267. (j) Lu, T.; Wang, J.-Y.; Tu, D.; Chen, Z.N.; Chen, X.-T.; Xue, Z.-L. Luminescent Mechanochromic Dinuclear Cu(I) Complexes with Macrocyclic Diamine-Tetracarbene Ligands. Inorg. Chem. 2018, 57, 13618-13630. (k) Feng, N.; Gao, C.; Guo, C.-Y.; Chen, G. Copper-Phenylacetylide Nanobelt/Single-Walled Carbon Nanotube Composites: Mechanochromic Luminescence Phenomenon and Thermoelectric Performance. ACS Appl. Mater. Interfaces 2018, 10, 5603-5608. (1) Hupp, B.; Nitsch, J.; Schmitt, T.; Bertermann, R.; Edkins, K.; Hirsch, F.; Fischer, I.; Auth, M.; Sperlich, A.; Steffen, A. Stimulus-Triggered Formation of an Anion-Cation Exciplex in Copper(I) Complexes as a Mechanism for Mechanochromic Phosphorescence. Angew. Chem. Int. Ed. 2018, 57, 13671-13675. (m) Liske, A.; Wallbaum, L.; Hölzel, T.; Föller, J.; Gernert, M.; Hupp, B.; Ganter, C.; Marian, C. M.; Steffen, A. Cu-F Interactions between 
Cationic Linear N-Heterocyclic Carbene Copper(I) Pyridine Complexes and Their Counterions Greatly Enhance Blue Luminescence Efficiency. Inorg. Chem. 2019, 58, 5433-5445. (n) Yang, M.; Chen, X.-L.; Lu C.-Z. Efficiently luminescent copper(I) iodide complexes with crystallization-induced emission enhancement (CIEE). Dalton Trans., 2019, 48, 10790-10794. (o) Vacher, A.; Amar, A.; Camerel, F.; Molard, Y.; Latouche, C.; Roisnel, T.; Dorcet, V.; Boucekkine, A.; Akdas-Kiliç H.; Achard, M. Modulation of emission properties of phosphinesulfonate ligand containing copper complexes: playing with solvato-, thermo-, and mechanochromism. Dalton Trans., 2019, 48, 2128-2134. (p) Hu, L.; Zheng, A.; Kang, Y.; Wen, T.; Zhang, J. A supersalt-type copper(I)thiolate cluster with applications for mechano/thermochromism and the oxygen evolution reaction. Chem. Commun., 2020, 56, 3967-3970.

(35) [ $\left.\mathbf{C u}_{4} \mathbf{I}_{4}\right]$-based clusters: (a) Perruchas, S.; Le Goff, X. F.; Maron, S.; Maurin, I.; Guillen, F.; Garcia, A.; Gacoin, T.; Boilot, J.-P. Mechanochromic and Thermochromic Luminescence of a Copper Iodide Cluster. J. Am. Chem. Soc. 2010, 132, 10967-10969. (b) Shan, X.-C.; Jiang, F.-L.; Zhang, H.-B; Qian, X.-Y.; Chen, L.; Wu, M.Y.; Al-Thabaiti, S. A.; Hong, M.-C. A solid AND logic stimuli-responsive material with bright nondestructive performance designed by sensitive cuprophilicity. Chem. Commun. 2013, 49, 10227-10229. (c) Shan, X.-C.; Jiang, F.-L.; Chen, L.; Wu, M.-Y.; Pan, J.; Wan, X.-Y.; Hong, M.-C. Using cuprophilicity as a multi-responsive chromophore switching color in response to temperature, mechanical force and solvent vapors. J. Mater. Chem. C, 2013, 4339-4349. (d) Shan, X.-C.; Zhang, H.-B.; Chen, L.; Wu, M.-Y.; Jiang, F.-L.; Hong, M.-C. MultistimuliResponsive Luminescent Material Reversible Switching Colors via Temperature and Mechanical Force. Cryst. Growth Des. 2013, 13, 1377-1381. (e) Benito, Q.; Le Goff, X. F.; Maron, S.; Fargues, A.; Garcia, A.; Martineau, C.; Taulelle, F.; Kahlal, S.; Gacoin, T.; Boilot, J.-P.; Perruchas, S. Polymorphic Copper Iodide Clusters: Insights into the Mechanochromic Luminescence Properties. J. Am. Chem. Soc., 2014, 136, 11311-11320. (f) Benito, Q.; Maurin, I.; Cheisson, T.; Nocton, G.; Fargues, A.; Garcia, A.; Martineau, C.; Gacoin, T.; Boilot, J.-P.; Perruchas, S. Mechanochromic Luminescence of Copper Iodide Clusters. Chem. Eur. J. 2015, 5892-5897. (g) Yang, K.; Li, S.-L.; Zhang, F.-Q.; Zhang, X.-M. Simultaneous Luminescent Thermochromism, Vapochromism, Solvatochromism, and Mechanochromism in a C3-Symmetric Cubane $\left[\mathrm{Cu}_{4} \mathrm{I}_{4} \mathrm{P}_{4}\right]$ Cluster without $\mathrm{Cu}-\mathrm{Cu}$ Interaction. Inorg. Chem. 2016, 55, 7323-7325. (h) Huitorel, B.; Benito, Q.; Fargues, A.; Garcia, A.; Gacoin, T.; Boilot, J.-P.; Perruchas, S.; Camerel, F. Mechanochromic Luminescence and Liquid Crystallinity of Molecular Copper Clusters. Chem. Mater. 2016 28, 8190-8200. (i) Huitorel, B.; El Moll, H.; Cordier, M.; Fargues, A.; Garcia, A.; Massuyeau, F.; Martineau-Corcos, C.; Gacoin, T.; Perruchas, S. Luminescence Mechanochromism Induced by Cluster Isomerization. Inorg. Chem. 2017, 56, 12379-12388. (j) Kobayashi, A.; Yoshida, Y.; Yoshida, M.; Kato, M. Mechanochromic Switching between Delayed Fluorescence and Phosphorescence of Luminescent Coordination Polymers Composed of Dinuclear Copper(I) Iodide Rhombic Cores. Chem. Eur. J. 2018, 24, 1475014759. (k) S.-Y. Yin, Z. Wang, Z.-M. Liu, H.-J. Yu, J.-H. Zhang, Y. Wang, R. Mao, M. Pan, C.-Y. Su, Inorg. Chem. 2019, 58, 10736-10742. (1) Huitorel, B.; Utrera-Melero, R.; Massuyeau, F.; Mevelec, J.-Y.; Baptiste, B.; Polian, A.; Gacoin, T.; Martineau-Corcos, C.; Perruchas, S. Luminescence mechanochromism of copper iodide clusters: a rational investigation. Dalton Trans. 2019, 48, 7899-7909.

(36) Wenger, O. S. Photoactive Complexes with Earth-Abundant Metals. J. Am. Chem. Soc. 2018, 140, 1352213533.

(37) Hamze, R.; Peltier, J. L.; Sylvinson, D.; Jung, M.; Cardenas, J.; Haiges, R.; Soleilhavoup, M.; Jazzar, R.; Djurovich, P. I.; Bertrand, G.; Thompson, M. E. Eliminating nonradiative decay in $\mathrm{Cu}(\mathrm{I})$ emitters: $>99 \%$ quantum efficiency and microsecond lifetime. Science 2019, 363, 601-606.

(38) Olaru, M.; Rychagova, E.; Ketkov, S.; Shynkarenko, Y.; Yakunin, S.; Kovalenko, M. V.; Yablonskiy, A.; Andreev, B.; Kleemiss, F.; Beckmann, J.; Vogt, M. A Small Cationic Organo-Copper Cluster as Thermally Robust Highly Photo- and Electroluminescent Material. J. Am. Chem. Soc. 2020, 142, 373-381.

(39) Yu, T.-L.; Guo, Y.-M.; Wu, G.-X.; Yang, X.-F.; Xue, M.; Fu, Y.-L.; Wang, M.-S. Recent progress of d ${ }^{10}$ iodoargentate(I)/iodocuprate(I) hybrids: Structural diversity, directed synthesis, and photochromic/thermochromic properties. Coord. Chem. Rev. 397, 2019, 91-111.

(40) Benito, Q.; Baptiste, B.; Polian, A.; Delbes, L.; Martinelli, L.; Gacoin, T.; Boilot, J.-P.; Perruchas, S. Pressure Control of Cuprophilic Interactions in a Luminescent Mechanochromic Copper Cluster Inorg. Chem. 2015, 54, 9821-9825. 
(41) Benito, Q.; Fargues, A.; Garcia, A.; Maron, S.; Gacoin, T.; Boilot, J.-P.; Perruchas, S.; Camerel, F. Photoactive Hybrid Gelators Based on a Luminescent Inorganic $\left[\mathrm{Cu}_{4} \mathrm{I}_{4}\right]$ Cluster Core. Chem. Eur J. 2013, 19, 47, 15831-15835.

(42) Utrera-Melero, R. ; Mevellec, J.-Y. ; Gautier, N. ; Stephant, N. ; Massuyeau, F. ; Perruchas, S. AggregationInduced Emission Properties of Copper Iodide Clusters. Chem. - Asian J., 2019, 14, 3166-3172.

(43) CSD Cambridge data base.

(44) Bondi, A. van der Waals volums and radii. J. Phys. Chem. 1964, 68, 441-451.

(45) Sculfort, S.; Braunstein, P. Intramolecular d10-d10 interactions in heterometallic clusters of the transition metals. Chem. Soc. Rev. 2011, 40, 2741-2760.

(46) Gaussian 16, Revision A.03, M. J. Frisch, G. W. Trucks, H. B. Schlegel, G. E. Scuseria, M. A. Robb, J. R. Cheeseman, G. Scalmani, V. Barone, G. A. Petersson, H. Nakatsuji, X. Li, M. Caricato, A. V. Marenich, J. Bloino, B. G. Janesko, R. Gomperts, B. Mennucci, H. P. Hratchian, J. V. Ortiz, A. F. Izmaylov, J. L. Sonnenberg, D. Williams-Young, F. Ding, F. Lipparini, F. Egidi, J. Goings, B. Peng, A. Petrone, T. Henderson, D. Ranasinghe, V. G. Zakrzewski, J. Gao, N. Rega, G. Zheng, W. Liang, M. Hada, M. Ehara, K. Toyota, R. Fukuda, J. Hasegawa, M. Ishida, T. Nakajima, Y. Honda, O. Kitao, H. Nakai, T. Vreven, K. Throssell, J. A. Montgomery, Jr., J. E. Peralta, F. Ogliaro, M. J. Bearpark, J. J. Heyd, E. N. Brothers, K. N. Kudin, V. N. Staroverov, T. A. Keith, R. Kobayashi, J. Normand, K. Raghavachari, A. P. Rendell, J. C. Burant, S. S. Iyengar, J. Tomasi, M. Cossi, J. M. Millam, M. Klene, C. Adamo, R. Cammi, J. W. Ochterski, R. L. Martin, K. Morokuma, O. Farkas, J. B. Foresman, and D. J. Fox, Gaussian, Inc., Wallingford CT, 2016. Gaussian, Inc.

(47) (a) Perdew, J. P.; Ernzerhof, M.; Burke, K. M. Rationale for Mixing Exact Exchange with Density Functional Approximations. J. Chem. Phys. 1996, 105, 9982-9985. (b) Perdew, J. P.; Burke, K.; Ernzerhof, M. Generalized Gradient Approximation Made Simple. Phys. Rev. Lett. 1996, 77, 3865-3868. (c) Perdew, J. P.; Burke, K.; Ernzerhof, M. Erratum: Generalized Gradient Approximation Made Simple. Phys. Rev. Lett. 1997, 78, 1396-1396. (48) (a) Dunning Jr., T. H.; Hay, P. J. Methods of Electronic Structure Theory, H. F. Schaeffer ed., Plenum Press, New York, 1977. (b) Hay, P. J.; Wadt, W. R. Ab initio effective core potentials for molecular calculations. Potentials for the transition metal atoms Sc to Hg. J. Chem. Phys. 198582 270-283. (c) Hay, P. J.; Wadt, W. R. $\mathrm{Ab}$ initio effective core potentials for molecular calculations. Potentials for main group elements Na to Bi. J. Chem. Phys. 198582 284-298. (d) Hay, P. J.; Wadt, W. R. Ab initio effective core potentials for molecular calculations. Potentials for K to Au including the outermost core orbitals. J. Chem. Phys. 1985, 82, 299-310.

(49) Burke, K.; Gross, E. K. U. A guided tour of time-dependent density functional theory. In Density Functionals: Theory and Applications, Lecture Notes in Physics, Vol. 500; Joubert, D., Ed.; Springer, 1998.

(50) Licari, D., Baiardi, A., Biczysko, M., Egidi, F., Latouche, C., Barone, V. Implementation of a Graphical User Interface for the Virtual Multifrequency Spectrometer: The VMS-Draw Tool. J. Comput. Chem. 2015, 36, 321334.

(51) Benito, Q.; Maurin, I.; Poggi, M.; Martineau-Corcos, C.; Gacoin, T.; Boilot, J.-B.; Perruchas, S. Impact of crystalline packing on the mechanochromic luminescence properties of copper based compounds: towards functional coatings. J. Mater. Chem. C, 2016, 4, 11231-11237.

(52) Benito, Q.; Le Goff, X.; Nocton, G.; Fargues, A.; Garcia, A.; Berhault, A.; Kahlal, S.; Saillard, J.-Y.; Martineau, C.; Trebosc, J.; Gacoin, T.; Boilot, J.-P.; Perruchas, S. Geometry Flexibility of Copper Iodide Clusters: Variability in Luminescence Thermochromism. Inorg. Chem. 2015, 54, 4483-4494.

(53) Tang, J. A.; Ellis, B. D.; Warren, T. H.; Hanna, J. V.; Macdonald, C. L. B.; Schurko, R. W. Solid-State ${ }^{63} \mathrm{Cu}$ and ${ }^{65} \mathrm{Cu}$ NMR Spectroscopy of Inorganic and Organometallic Copper(I) Complexes. J. Am. Chem. Soc. 2007, $129,13049-13065$.

(54) Martineau, C.; Fayon, F.; Legein, C.; Buzare, J.-Y.; Silly, G.; Massiot, D. Accurate heteronuclear J-coupling measurements in dilute spin systems using the multiple-quantum filtered J-resolved experiment. Chem. Commun. 2007, 2720-2722.

(55) Huitorel, B.; El Moll, H. ; Utrera-Melero, R. ; Cordier, M. ; Fargues, A. ; Garcia, A. ; Massuyeau, F. ; Martineau-Corcos, C. ; Fayon, F. ; Rakhmatullin, A.; Kahlal, S. ; Saillard, J.-Y. ; Gacoin, T. ; Perruchas, S. Evaluation of Ligands Effect on the Photophysical Properties of Copper Iodide Clusters. Inorg. Chem. 2018, 57, 4328-4339.

(56) Bowmaker, G. A.; Healy, P. C. The characterization of tetrameric complexes of copper(I) halides with phosphine and amine ligands by far infrared spectroscopy. Spectrochimica Acta Part A: Molecular Spectroscopy 1988, 44, 115-119. 
(57) Bowmaker, G. A.; Knappstein, R. J.; Tham, S. F. An Infrared and Raman Spectroscopic Study of Some Group 1B Halide Complexes Containing an $\mathrm{M}_{4} \mathrm{X}_{4}$ Core. Aust. J. Chem., 1978, 31, 2137-2143.

(58) Attar, S.; Bowmaker, G. A.; A1 cock, N. W.; Frye, J. S.; Bearden, W. H.; Nelson, J. H. Phosphole Complexes of Copper(I) Halides. Investigations of Structure and Bonding by X-ray Crystallography, Infrared Spectroscopy, and CP/MAS ${ }^{31}$ P NMR Spectroscopy. Inorg. Chem. 1991, 30, 4143-4153.

(59) (a) Vitale, M.; Ryu, C. K.; Palke, W. E.; Ford, P. C. Ab Initio Studies of the Copper(I) Tetramers $\mathrm{Cu}_{4} \mathrm{X}_{4} \mathrm{~L}_{4}$ (X $=\mathrm{I}, \mathrm{Br}, \mathrm{Cl}$ ). Effects of Cluster Structure and of Halide on Photophysical Properties. Inorg. Chem. 1994, 33, 561.

(b) De Angelis, F.; Fantacci, S.; Sgamellotti, A.; Cariati, E.; Ugo, R.; Ford, P. C. Electronic Transitions Involved in the Absorption Spectrum and Dual Luminescence of Tetranuclear Cubane $\left[\mathrm{Cu}_{4} \mathrm{I}_{4}(\text { pyridine })_{4}\right]$ Cluster: a Density Functional Theory/Time-Dependent Density Functional Theory Investigation. Inorg. Chem. 2006, 45, 10576. (c) Vega, A.; Saillard, J.-Y. Bonding in Tetrahedral $\mathrm{Cu}_{4}\left(\mu_{3}-\mathrm{X}\right)_{4} \mathrm{~L}_{4}$ Copper(I) Clusters: A DFT Investigation. Inorg. Chem. 2004, 43, 4012-4018.

(60) Perruchas, S.; Tard, C.; Le Goff, X. F., Fargues, A.; Garcia, A.; Kahlal, S.; Saillard, J.-Y.; Gacoin, T.; Boilot, J.-P. Thermochromic Luminescence of Copper Iodide Clusters: The Case of Phosphine Ligands. Inorg. Chem. 2011, 50, 10682-10692.

(61) Latouche, C.; Liao, J.-H.; Li, Y.-J.; Shiu, R.-Y.; Barone, V.; Kahlal, S.; Liu, C. W.; Saillard, J.-Y. Encapsulating Iodine and Copper Into Copper(I) Clusters Stabilized by Dichalcogenolate Ligands: Stability, Structure, and Optical Properties. Inorg. Chem. 2017, 56, 22, 14135-14146.

\section{For Table of Contents Only}

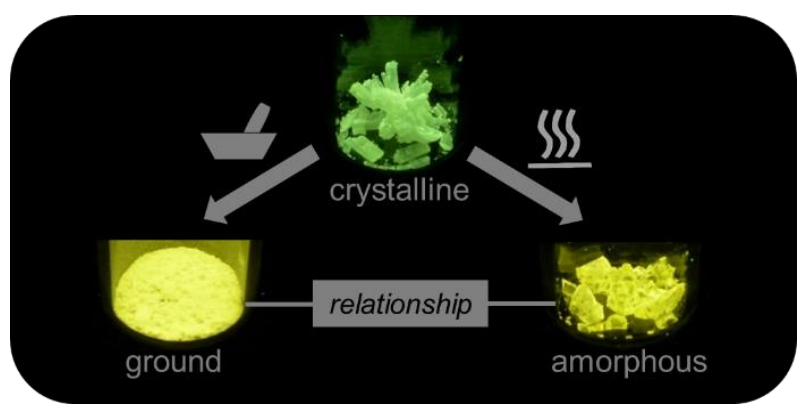

The mechanochromic luminescence properties of a cubane copper iodide cluster which presents two crystalline polymorphs and forms a fully amorphous phase upon melting, are described. Photophysical and structural analysis supported by theoretical study permit to get insights into the mechanochromism mechanism with the amorphous state representing the ultimate state of the mechanically induced crystalline-to-amorphous transformation. 